\title{
AIR-BEARING SPINDLE FOR PRODUCTION MACHINE TOOLS
}

\author{
P. J. Steger \\ L. A. Abbatiello
}

\section{UNION CARBIDE CORPORATION}

NUCLEAR DIVISION

OAK RIDGE Y-12 PLANT

operated for the ATOMIC ENERGY COMMISSION under U. S. GOVERNMENT Contract $W-7405$ eng 26

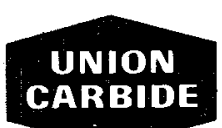

OAK RIDGE Y.12 PLANT

P. O. BOX Y

OAK RIDGE, TENNESSEE
37830

This document is PUELICLY RELEASABLE:

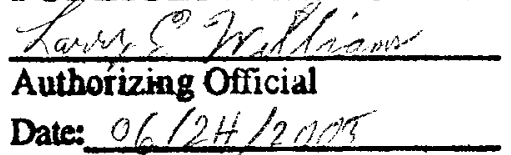

DISTRIBUTION OF THIS DOCUMENI IS URUUAATSD 
Printed in the United States of Americo. Available from Clearinghouse for Federal Scientific and Technical Information, National Bureou of Standards,

U.S. Department of Commerce, Springfield, Virginia 22151

Price: Printed Copy $\$ 3.00$; Microfiche $\$ 0.65$

LEGAL NOTICE

This report was prepared as an account of Government sponsored work. Neither the United States, nor the Commission, nor any person acting on behalf of the Commission:

A. Makes ony warranty or representation, expressed or implied, with respect to the accuracy, completeness, or usefulness of the information contained in this report, or that the use of any information, apparatus, method, or process disclosed in this report may not infringe privately owned rights; or

B. Assumes any liabilities with respect to the use of, or for damages resulting from the use of any information, apparatus, method, or process disclosed in this report.

As used in the above, "person acting on behalf of the Commission" includes any employee or confractor of the Commission, or employee of such contractor, to the extent that such employee or contractor of the Commission, or employee of such contractor prepares, disseminates, or provides access to, any information pursuant to his employment or contract with the Commission, or his employment with such contractor. 
密. $3.00,0.5$

Date Issued: September 25, 1967

Document $Y-1578$

Engineering and Equipment TID -4500

\section{UNION CARBIDE CORPORATION \\ Nuclear Division}

\section{Y-12 PLANT}

Contract W-7405-eng-26

With the US Atomic Energy Commission

\section{AIR-BEARING SPINDLE FOR PRODUCTION MACHINE TOOLS}

P. J. Steger

L. A. Abbatiello

LE G A L N N OTICE
Shis report was prepared as an account of

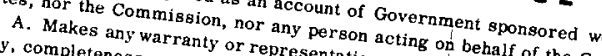

racy, completeness, or useful representation, expres behalf of the Commiseither the United

of any information, apparatulness of the information er implied, with respion:

privately owned rights; or use of Assumes any liab

As used in then, apparatus, methoct to the use of, or for the report may not infringe ployee or contra the above, "tus, method, or process disclosed damages resulting from the such employee or of the Commission, or behaif of the Commists report.

disseminates, or providestor of the Commission, or of such contractor, includes any em-

with the Commission, or his emp to, any information employee of such contractoriont extent that

or his employment with such contractort to his employment prepares,

Oak Ridge, Tennessee 
Document $Y-1578$

Engineering and Equipment TID-4500

Distribution:

Abbatiello, L. A. (10)

Ackerson, R. D. (AFSC)

Bailey, E. W.

Ballenger, $H$. F.

Bernander, N.K.

Burkhart, L. E.

Christman, A. M.

Ebert, J. W.

Ellingson; R. D.

Evans, G. W.

Gritzner, V. B.

Harwell, W. L. (ORGDP) (5)

Hemphill, L. F.

Hensley, C. E.

Huber, A.P.

(ORGDP)

IMOG

Jordan, R. G.

(ORGDP)

Keller, C. A.

(AEC-ORO)(4)

Little, J. C.

McLendon, J. D.

Meeks, E. J.

\author{
Mitchel, G.W. \\ Oliphant, G.W. \\ Perry, A. E. \\ Phillips, L. R. \\ Rader, D. H. \\ Schwenn, M. F. \\ Sommerfeld, K. W. \\ Stoner, H. H. \\ Steger, P. J. \\ Tilson, F. V. \\ Trotter, T. C. \\ Waters, J. L. \\ Wesley, R. L. \\ Whitson, W. K. \\ Winkel, R. A. \\ (Paducah) \\ Wood, D. C. \\ Yaggi, W. J. \\ Zurcher, E. \\ $Y-12$ Central Files \\ $Y-12$ Central Files $(Y-12 R C)$
}

In addition, this report is distributed in accordance with the category Engineering and Equipment, as given in the "USAEC Standard Distribution Lists for Unclassified Scientific and Technical Reports", TID-4500. 


\section{ABSTRACT}

A production-sized, externally pressurized and air-lubricated spindle, capable of supporting 400-pound cantilevered loads, was fabricated for use in a program designed to improve the accuracy of a Heald 15 by 15 -inch numerically controlled turning and boring machine tool. Heat generation in the precision ball bearings of the original spindle gave indications of being a significant source of inaccuracy in parts machined on the lathe. Because of the low friction and subsequent low heatgeneration characteristics of the air bearing, the spindle was successfully used to reduce the associated errors, while providing improved rotational accuracy. 
THE AIR-BEARING SPINDLE.

Spindle Design :

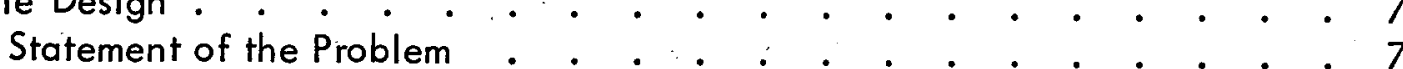

General Requirements .. . . . . . . . . . . . . . . 7

Basic Construction . . . . . . . . . . . . . . . . . 8

Design Considerations . . . . . . . . . . . . . . . . 9

Spindle Fabrication. . . . . . . . . . . . . . . . . . 21

Spindle Assembly . . . . . . . . . . . . . . . . . . . . . . . 29

Spindle Evaluation . . . . . . . . . . . . . . . . . . . . . . .

Stiffness . . . . . . . . . . . . . . . . . . . 30

Rotational Accuracy. . . . . . . . . . . . . . . . 31

Growth . . . . . . . . . . . . . . . . . . . 32

Repeatability. . . . . . . . . . . . . . . . . . . . .

Rotational Accuracy Under Load . . . . . . . . . . . . . . . . . 39

Bearing Durability . . . . . . . . . . . . . . . . 40

APPENDIX . . . . . . . . . . . . . . . . . . . . . 41

Flexure Ring Deformation . . . . . . . . . . . . . . . . 41

REFERENCES . . . . . . . . . . . . . . . . . . . . 44

AVAILABLE DRAWINGS . . . . . . . . . . . . . . . . 45 


\section{SUMMARY}

An externally pressurized air-bearing spindle was fabricated and installed on a 15 by 15 -inch numerically controlled turning and boring machine tool at the Oak Ridge $Y-12$ Plant. The addition of this spindle, along $w$ ith other modifications, resulted in a machine tool with a contouring capability of \pm 200 microinches. (1)

The spindle was designed to replace the existing precision ball-bearing spindle and to meet the load requirements of the machine tool while providing thermal stability and improved rotational accuracy. Measurements of the operational characteristics of the fabricated spindle indicate that the design requirements were met or exceeded.

Results of the investigation demonstrated the following:

1. Porous carbon-graphite material, through which air is supplied to the bearing film, makes an excellent pad material.

2. The self-lubricating properties of the graphite provide backup protection for the journals in event of rubbing due to shock loading or loss of air pressure.

3. Spindle heat generation was reduced to levels which cause a housing temperature rise of less than $2^{\circ} \mathrm{F}$ at $1,000 \mathrm{rpm}$.

4. Rotational accuracies of the spindle are better than 12 microinches, measured over the entire speed range of the spindle.

Two years of satisfactory operation of this spindle at $Y-12$ indicates that externally pressurized air-bearing spindles of this design are suitable for routine production use. Air-bearing spindles are no longer confined to high-speed and low dynamic loading applications. Instead, they are now able to compete favorably with precision "ball-bearing machine-tool spindles where high load capability and high dynamic stability are required, while providing the advantages of excellent thermal stability, rotational accuracy, and reliability. Impetus given by the performance of this prototype spindle has resulted in an improved spindle design which is presently undergoing tests at the $Y-12$ Plant. (2) 


\section{INTRODUCTION}

One of the major sources of error in precision tape-controlled turning and boring machine tools is the thermal effects produced by heat generation in the bearings of the spindle. Many times the full accuracy potential of the machine tool cannot be realized because of temperature-related changes which occur in the machine structure and components. This condition results in a change of the desired tool-path position relative to a predetermined part center, causing part inaccuracies.

Because of the well-known low heat generation and subsequent thermal stability of externally pressurized air bearings, it was felt that a machine tool spindle which possessed bearings of this nature would eliminate one of the major heat sources and thus improve machine-tool accuracy. 


\section{THE AIR-BEARING SPINDLE}

\section{SPINDLE DESIGN}

\section{Statement of the Problem}

From studying the characteristics of a Heald 15 by 15 -inch numerically controlled turning and boring machine tool, it was found that the accuracy of the machine tool was being hampered by the thermally related changes that occur in the machine structure and components. A major source of this heat was the spindle bearings. There are several methods available for reducing the thermal errors resulting from the spindle heat generation: (1) measurement and compensation, (2) use of heat removal equipment, or (3) elimination of the source of errors. Available data on externally pressurized air bearings indicated that a spindle with this type of bearing would be thermally stable over the normal range of machine-tool spindle speeds. (3)

Generally, the performance specifications for the air spindle required that the spindle be capable of replacing the existing ball-bearing spindle on a Heald 15 by 15inch Aximatic tape-controlled turning and boring machine tool, and that an improvement in thermal stability and rotational accuracy be realized while maintaining the load-carrying capacity and radial and axial stiffness or reliability of the machine.

Since efforts to procure a suitable air-bearing spindle commercially were unsuccessful, it was decided to design and fabricate the spindle in house. Conventional recessedpad designs were unsatisfactory because of poor dynamic stability and reliability due to bearing failure upon the introduction of foreign material, loss of air pressure, or rubbing due to shock loading. In comparison, the nonrecessed multi-orifice designs were more satisfactory, but they resulted in lower unit film stiffness and added fabrication costs; consequently, an unconventional design was selected. As the result of experimental work performed by T. G. Lewis $(4)$ at the E.I. du Pont de Nemours Laboratories in Wilmington, Delaware, a design was obtained which, when successfully scaled up, provided high unit stiffness, dynamic stability, and high reliability at film pressures of $100-120$ psig.

\section{General Requirements}

To meet the general performance requirements, the following design specifications were imposed on the spindle:

1. Axial and radial accuracy of the spindle stould be within 25 microinches TIR at a point six inches in front of the faceplate.

2. The spindle should be capable of supporting a 400-pound load with its center of gravity located six inches in front of the faceplate. 
3. The axial and radial stiffness should be such that the maximum rate of deflection will not exceed 2.5 microinches/pound measured at a point six inches in front of the faceplate.

4. The spindle should be capable of speeds up to $1,500 \mathrm{rpm}$ while maintaining all previously stated conditions.

5. The spindle should be capable of replacing the existing spindle on the Heald tape-controlled machines without any significant increase in weight or imposing any other limitation upon the machine as it is now designed. This requirement dictated the following physical limitations: maximumheight of centerline above the spindle base - 10 inches, maximum length possible - 36 inches, and the maximum allowable weight $-1,200$, pounds.

6. Temperature effects due to bearing heat generation are limited to a maximum housing temperature rise of $2^{\circ} \mathrm{F}$ above ambient at $1,000 \mathrm{rpm}$, and a maximum forward spindle movement due to temperature of 150 microinches at 1,000 rpm.

Basic Construction

A cross section of the basic spindle construction ispresented in Figure 1. Essentially, it consists of a stainless steel shaft hydrostatically supported by air in two journal bearings and restrained axially by two thrust bearings, one on each end.'

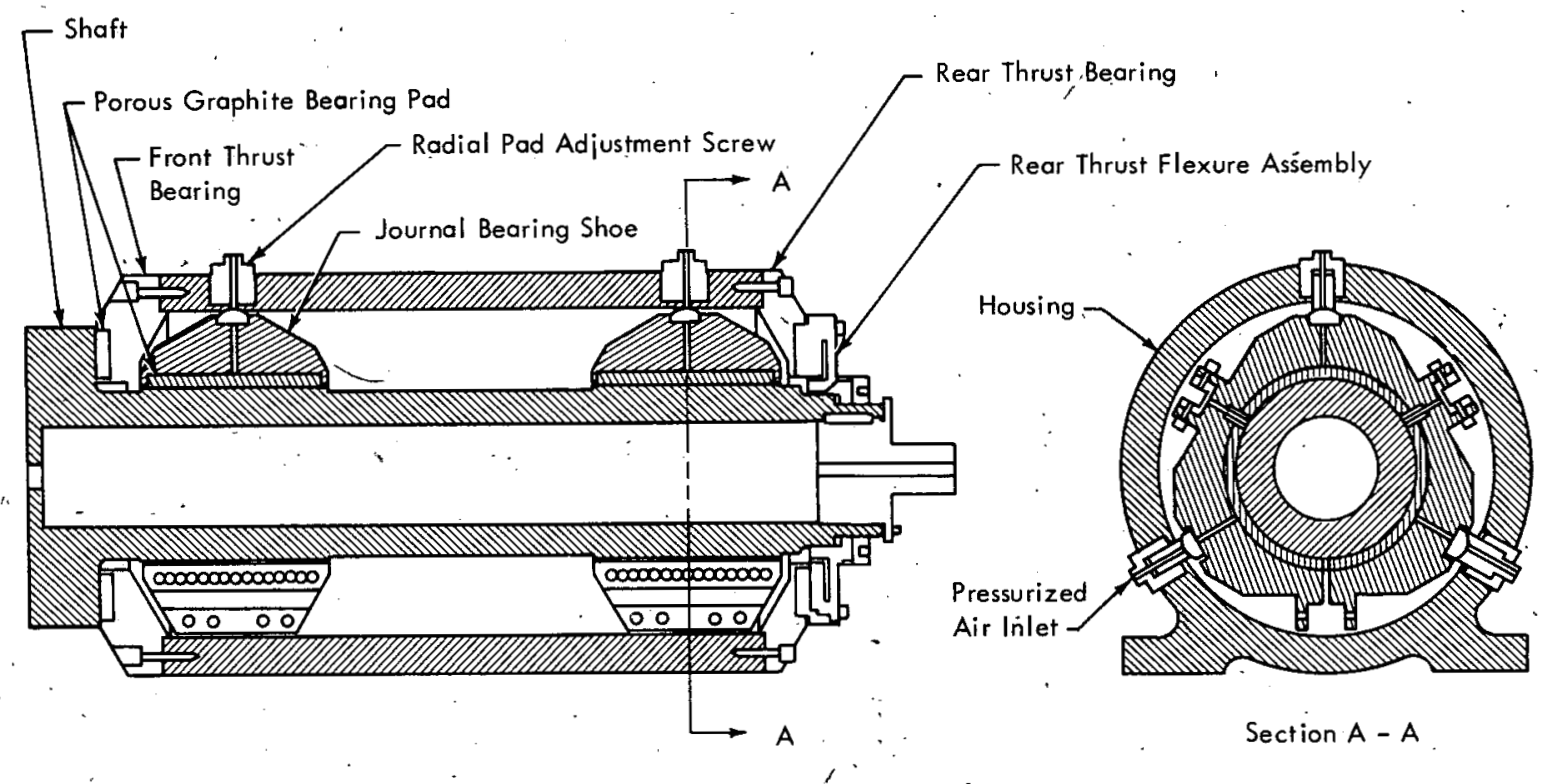

Figure 1. CROSS SECTION OF THE HYDROSTATIC AIR-BEARING SPINDLE. 
The journal bearings are of a three-shoepivoting design and supported by the housing through differential screw assemblies. The pivoting design permits self alignment of the bearings to the housing while the differential screwsprovide a means of adjusting the radial clearance between the shaft and bearings. This step is made possible by using flexure units to join the three shoes, as shown in Figure 1. By offering restraint to any rotary motion about a radial axis that could be caused by bearing contamination or friction, this arrangement reduces the possibility of bearing damage.

The two thrust bearings are arranged to allow the rear thrust bearing to take up spindle growth through a flexure unit. This unit is prestressed an amount equal to the force exerted by the film pressure acting over its area. This arrangement also permits adjustment of the film thickness in the thrust bearing and at the same time can take up axial expansion of the shaft due to temperature change and material strain. The unit was designed for a maximum deflection-to-force ratio within the permissible stress limits of the material.

Air is supplied to the bearing film through a porous graphite material which provides the pressure compensation necessary for externally pressurized bearing systems. There are two advantages to be gained from this construction: First, it provides a dynamically stable bearing since compensation occurs at the film, while maintaining a relatively flat pressure profile in the film due to air in jection over its entire surface. Second, because of the self-lubricating property of graphite and the full surface area of the bearing pad, backup protection is provided for the journals in the event of rubbing due to momentary overload or loss of air pressure in the film. A breakdown of one of the journal shoes showing the carbon liner and air-distribution grooves is presented in Figure 2.

\section{Design Considerations}

In designing the spindle, consideration had to be given to the deflection characteristics in order that the general load-carrying and stiffness requirements would be met. Deflections considered in the design resulted from a bending of the shaft and the change in the bearing film thickness due to the load reaction force acting at the bearing.

Bearing film stiffness was determined from an experimental bearing test device, presented in Figure 3 . The test device consisted of a $11 / 2$ by 4 -inch flat porous graphite bearing with an adjustable orifice in series with the graphite pad and included the means for measuring gas flow, film thickness, and pressure distribution in the film. The bearing film pressure versus thickness characteristics obtained with the device for different orifice settings are graphically presented in Figure 4 . Film stiffness is equal to the inverse of the slope of the curve at the point of normal operation. The adjustable orifice was used in series with the porous graphite material to permit obtaining different pressure compensation for the same bearing. Past 


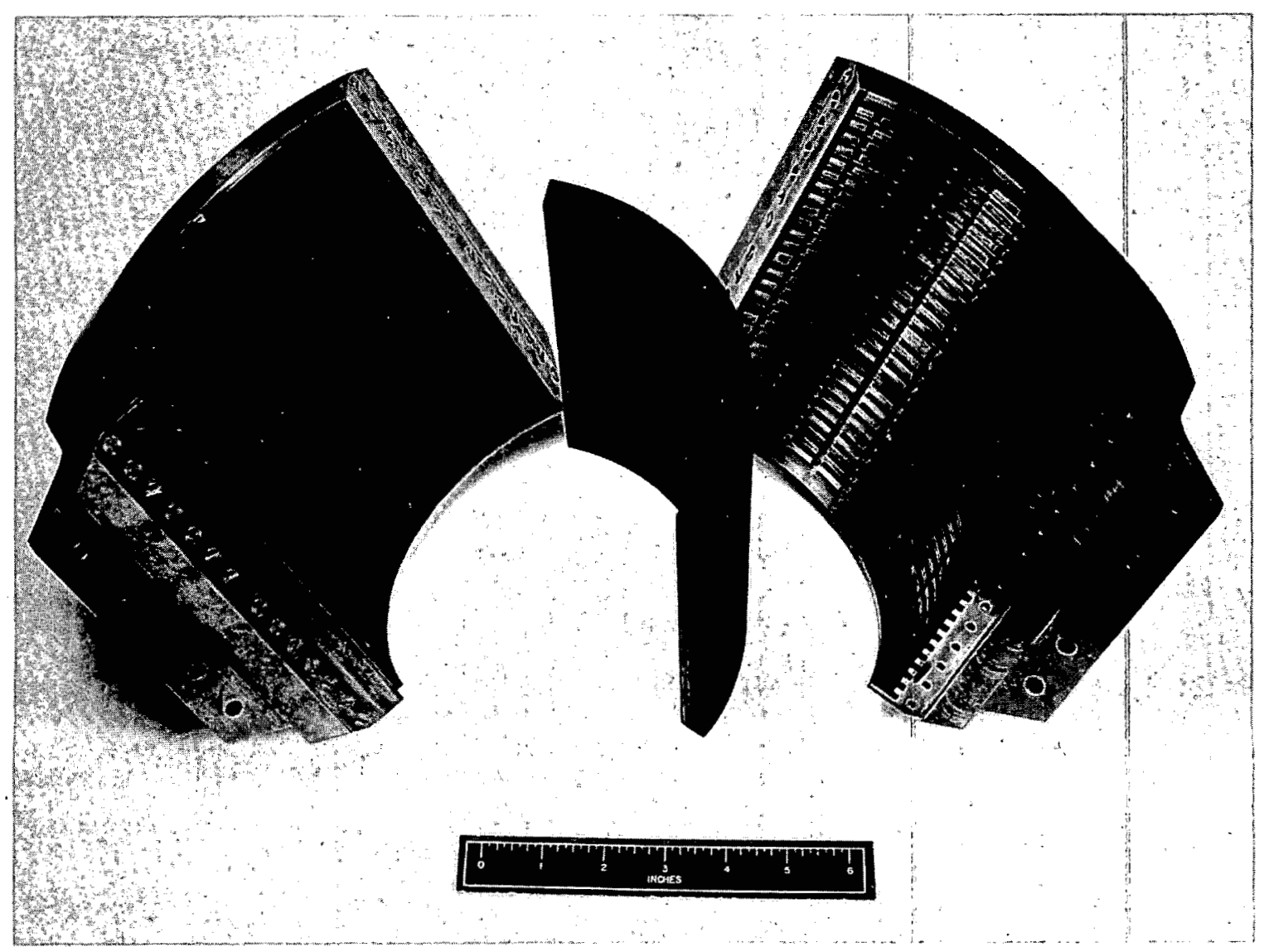

Figure 2. BREAKDOWN OF THE JOURNAL BEARING SHOE.

experience has indicated that although a variety of porous graphites will provide sufficient damping or a pressure drop to obtain a dynamically stable bearing film, there is considerable variation in the permeability of the material. To obtain a specific pressure drop before the film, which is needed for optimum stiffness, it is necessary to use an orifice in series with the graphite.

Reasonably accurate results for predicting radial deflections in the spindle were obtained using a resultant force system and treating the shaft as a free beam. The force system, considered to be acting on the spindle shaft, is shown in Figures 5 and 6. For these calculations, the following nomenclature is used:

A for the effective projected area of the journal, in square inches;

$R_{f}$ for the reaction at the front bearing, in pounds;

$R_{r}$ for the reaction at the rear bearing, in pounds;

$S$ for the bearing film stiffness, in pounds per inch per square inch; 


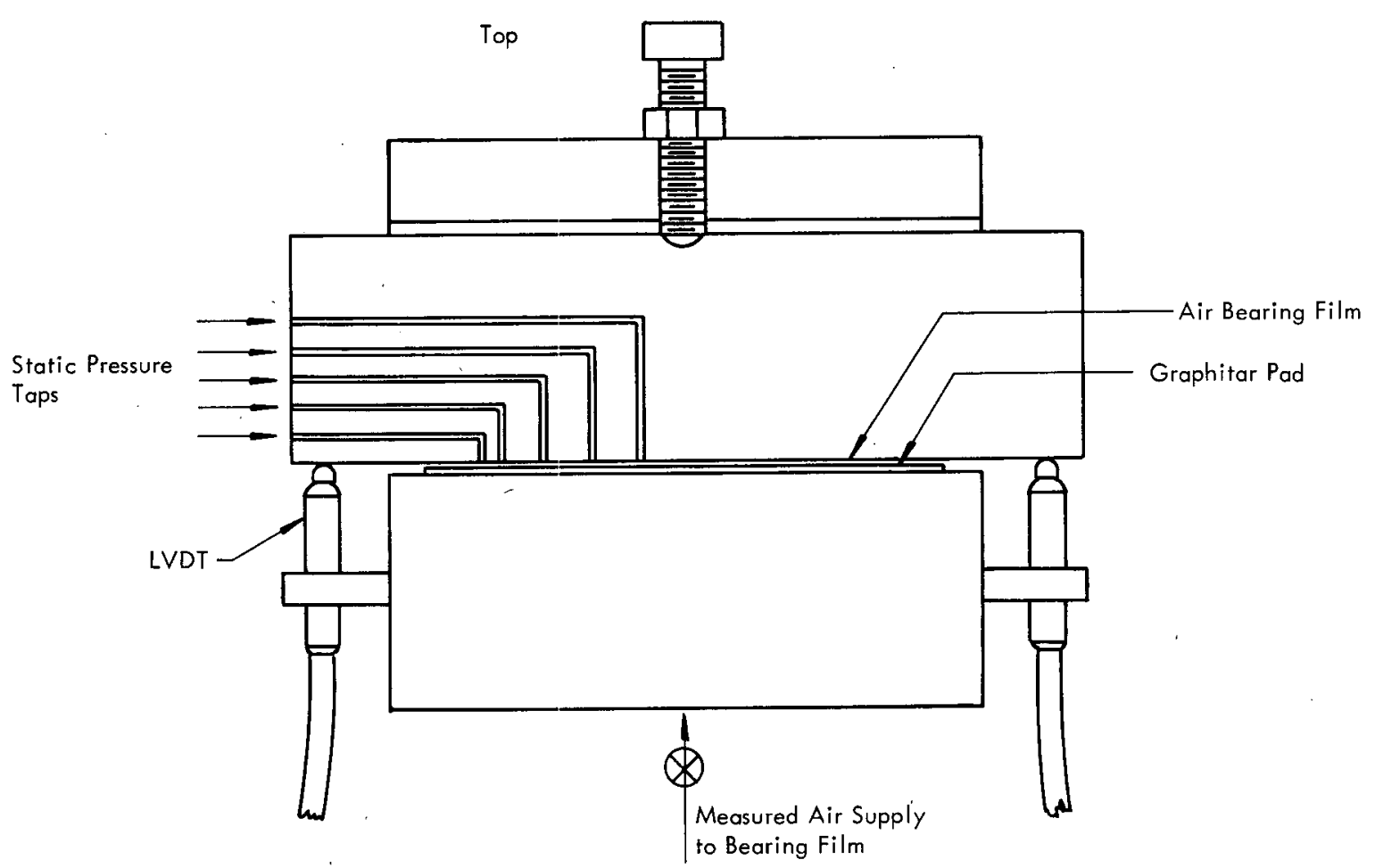

Figure 3. TEST DEVICE FOR MEASURING BEARING FILM STIFFNESS.

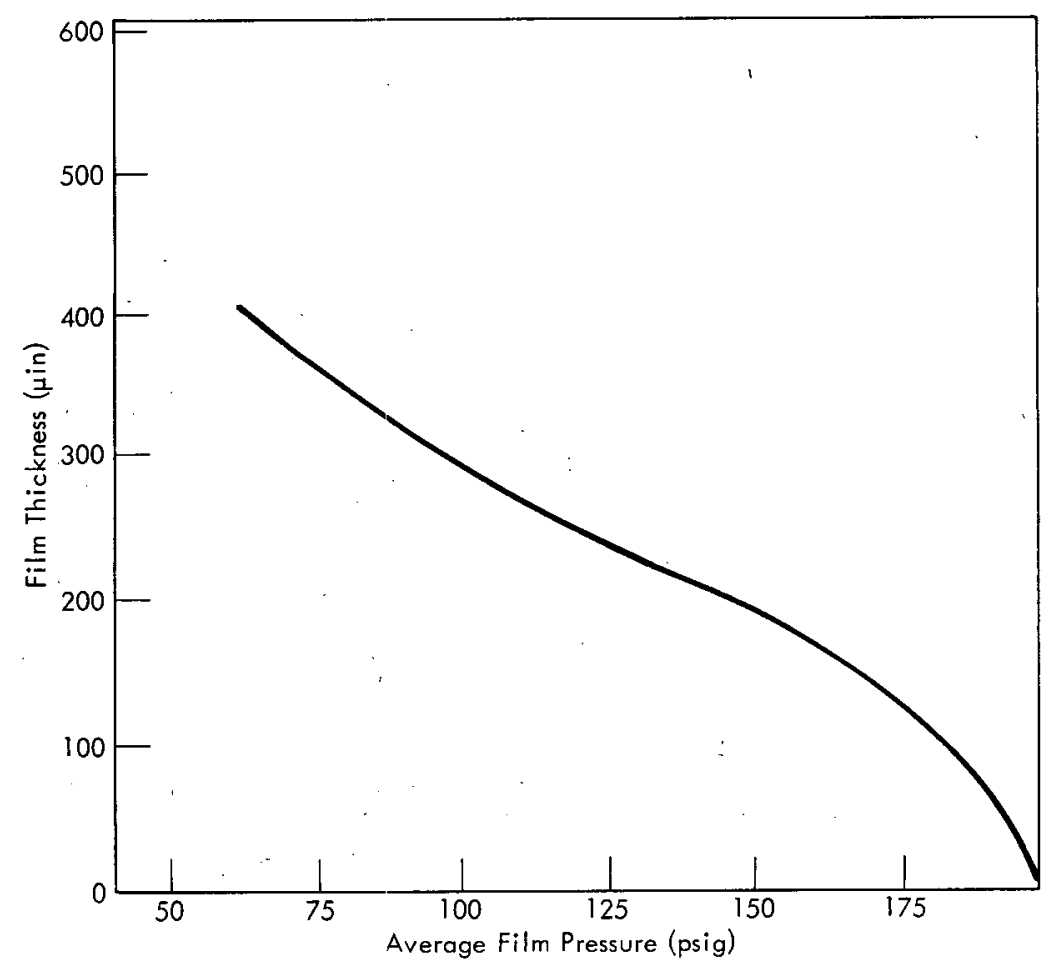

Figure 4. BEARING FILM DEFLECTION. 


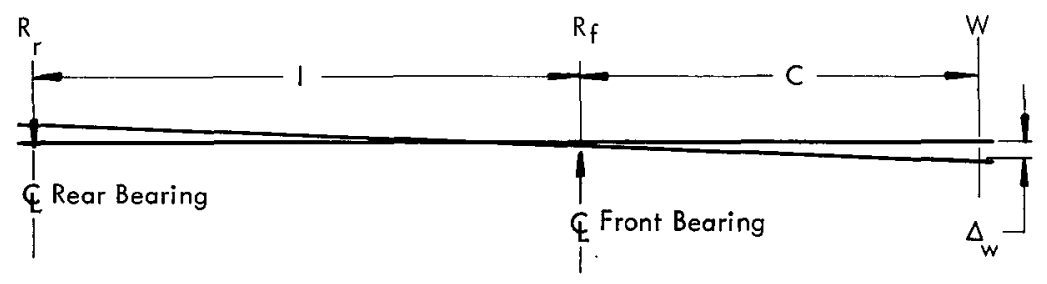

Figure 5. SPINDLE FORCE SYSTEM.

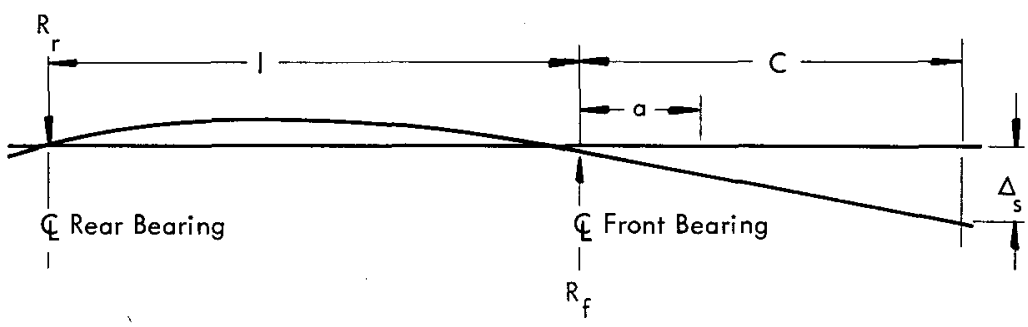

Figure 6. SIMPLE BEAM CONCEPT FOR DETERMINING SHAFT DEFLECTION.

$W$ for the load that is six inches in front of the spindle face, in pounds;

I for the moment of inertia, in inches 4 ;

I for the shaft length between bearing centerlines, in inches;

c for the length from the point of application to the front bearing centerline, in inches;

a for the distance between the front bearing centerline and the front thrust bearing, in inches;

$\Delta_{f}$ for the film deflection at the front bearing, in inches;

$\Delta_{r}$ for the film deflection at the rear bearings, in inches;

$\Delta_{S}$ for the shaft deflection at the load position, in inches;

$\Delta_{t}$ for the total deflection at the load position, in inches; and

$\Delta_{w}$ for the film deflection at the load position, in inches.

In calculating the film deflection, only the projected area opposed to the load is normally used; however, the area in line with the load is also used since it has a decreasing pressure acting on it as a result of film-thickness increase. With reference to the loading diagram shown in Figure 5, the film deflections are calculated as follows: 


$$
\Delta_{f}=\frac{W(I+c)}{2 I A S} \text { and } \Delta_{r}=\frac{W c}{2 I A S} \text {. }
$$

The film stiffness, as determined from the flat-pad experimental device for a bearing film thickness of 300 microinches and a film pressure of 100 psig, was 380,000 pounds per inch per square inch of bearing area. For the journal bearing calculation, this value was modified to take into account the nonuniform change in film thickness around the journal. For small changes in eccentricity, the modified value for film stiffness and that used in the calculations was $300,000 \mathrm{lbs} / \mathrm{in} / \mathrm{in}^{2}$. For a one-pound load acting at W and for an " $I$ " of 18 inches and a " $c$ " of 15 inches, the calculation is:

$$
\Delta_{f}=\frac{(18+15)}{2(18)(49)\left(3.0 \times 10^{5}\right)}=0.062 \text { microinch, and }
$$

$$
\Delta_{r}=\frac{15}{2(18)(49)\left(3.0 \times 10^{5}\right)}=0.028 \text { microinch. }
$$

Therefore:

$$
\Delta_{\mathrm{w}}=\frac{1+c}{l} \Delta_{\mathrm{f}}+\frac{c}{l} \quad \Delta_{\mathrm{r}}=0.137 \text { microinch. }
$$

Shaft deflection at the point six inches from the face was calculated using the following equations:

$$
Y_{a}=\frac{W c a^{2}}{2 E I}-\frac{W^{3}}{6 E I}+\frac{2 W c l a}{6 E I} \text { (deflection at "a"), }
$$

and

$$
\left(\frac{d y}{d x}\right)_{a}=\frac{W c a}{E I}-\frac{W_{a}^{2}}{2 E I}+\frac{W c l}{3 E I} \text { (slope of the shaft at "a"). }
$$

So:

$$
\Delta_{s}=Y+(c-a)\left(\frac{d y}{d x}\right)_{a}
$$

For a one-pound load acting at $W$ and for an "I" of 18 inches, a "c" of 15 inches, and an "a" of 9 inches, the calculation gives:

$$
\begin{aligned}
& Y=0.412 \text { microinch, } \\
& \left(\frac{d y}{d x}\right)_{a}=0.059 \text { microinch, and } \\
& \Delta_{S}=0.766 \text { microinch. }
\end{aligned}
$$


The total radial deflection at $W$ is:

$$
\Delta_{t}=\Delta_{W}+\Delta_{s}=0.903 \text { inch per pound of load. }
$$

Axial deflection in the thrust-bearing film due to axial tool forces is calculated as follows:

$$
\Delta_{a}=\frac{W}{A_{t}(S)}=\frac{1}{61\left(3 \times 10^{5}\right)}=0.054 \text { microinch per pound of tool force. }
$$

In addition, housing deflection, pad-support deflection, and pad bending and resultant change in film thickness and characteristics also contribute to the movement of the workpiece during machining. Because of the geometry involved and the difficulty of relating the interactions of the forces acting on the bearing system, no attempt was made to calculate these deflections. As indicated from past experience, these deflections would be small compared to the shaft and film deflections.

The deflection of any member in the bearing which could cause a change in the air-film thickness at any bearing surface was considered important. The members which fall into this classification were the bearing shoes, thrust runners, and thrust pads. The main consideration is that the bearing-member deflection does not cause variations of more than 50 percent in the desired air-film thickness. This goal can be accomplished in two ways: (1) by limiting the absolute deflections with respect to a reference to that specified; (2) by holding the slopes of the mating bearing surfaces parallel within the specified limits.

The geometry of these members makes an exact analysis of the deflections very difficult and time consuming. Since there is considerable margin for error involved, it was felt that the analysis could be approximated with sufficient accuracy by assuming the members to be composed of a series of cantilevered beams of one unit width. The beams were considered straight and uniformly loaded. For the thrust bearings and runners, cross-section depth was determined from:

$$
t=\left(\frac{3 P(R-r)^{4}}{2 E S}\right)^{1 / 3}
$$

where:

$P$ represents the film pressure in pounds per square inch,

$\mathrm{R}$ the outer radius in inches,

$r$ the inner radius in inches, 
E the modulus of elasticity in pounds per square inch,

$S$ the maximum allowable deflection in inches, and

$t$ the cross-section depth in inches.

For the journal-bearing shoes, the equation was modified to that of a straight constant-strength beam with a uniformly distributed load over its entire length:

$$
t=\left(\frac{\left.3 P\right|^{4}}{2 E S}\right)^{1 / 3}
$$

where:

I represents the length of the journal bearing shoe in inches, and

t the cross section depth at the center of the shoe in inches.

Since the curved length of the shoe is approximately the same as the axial length and the deflection of a curved beam will be less than that of a straight beam, the cross-section depth determined by the equation is satisfactory for both shoe directions.

Heat is generated in a hydrostatic bearing due to the shearing friction in the film as the shaft rotates. Since one of the prerequisites of this spindle was thermal stability, it was necessary to consider this factor in its design. Heat generated in the bearings can be calculated from the following equations derived from Newton's basic equation for viscous drag: $(3)$

for the thrust bearings -

$$
E_{f}=\frac{N^{2} \mu}{58.05 h} \cdot\left(R^{4}-R_{o}^{4}\right),
$$

for the journal bearings -

$$
E_{f}=0.0659 \frac{\mu \mu^{3} \mathbb{N}^{2}}{h} ;
$$

in each case,

$$
Q=\frac{E_{f}}{12 J},
$$


where:

$E_{f}$ represents the frictional moment per unit of time in inch-pounds per second,

$N$ the speed in revolutions per minute,

$\mu$ the viscosity in pound-seconds per square inch,

$h$ the film thickness in inches,

$R_{0}$ the inner radius of thrust in inches,

$R$ the outer radius of thrust in inches,

$r$ the radius of journal in inches,

I the length of journal in inches,

J a constant that equals 9,336 inch-pounds per Btu, and

$Q$ the heat generated per unit of time in Btu's per second.

The equation shown for heat generating in the journal bearings is exact only for the case of zero eccentricity between the shaft and bearings; but, it is sufficiently accurate for eccentricity values up to 0.5 , which will cover all normal load applications.

Heat generated in the bearings was calculated for a range of film thicknesses and speeds. The values obtained are shown graphically in Figures 7 and 8 . These values are for a journal-bearing diameter of seven inches, a thrust-bearing outer diameter of 11.75 inches, and an inner diameter of 7.75 inches.

Bearing heat dissipation from the spindle takes place by absorption by the bearing air and by a combination of convection and radiation from the shaft and housing to the surrounding atmosphere. Because of the small area of the mounting pads, conduction into the spindle mounting plate was ignored.

Because of the spindle geometry of composite materials used in fabrication, an exact theoretical analysis of the spindle heat transfer would be a formidable problem. As a result, a simplified approach was used to obtain an estimate of the bearing temperature rise which would occur.

From the geometry of the spindle, it can be seen that the heat will be dissipated from the shaft at the face in the front and from the balance ring, flexure ring, and coupling in the rear. Heat flowing into the housing will leave by convection and radiation to the atmosphere. 


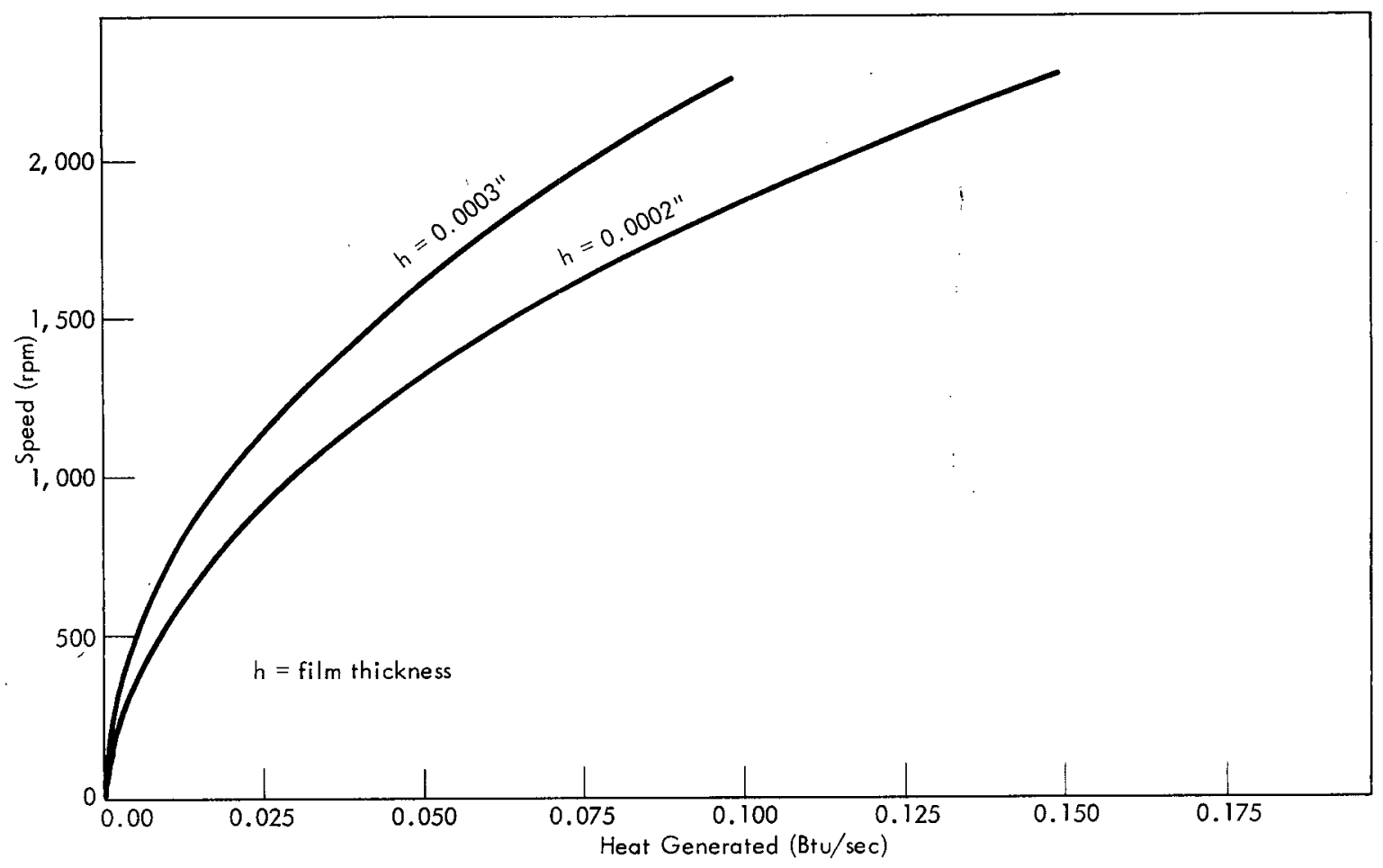

Figure 7. HEAT GENERATED IN JOURNAL BEARINGS.

$=$

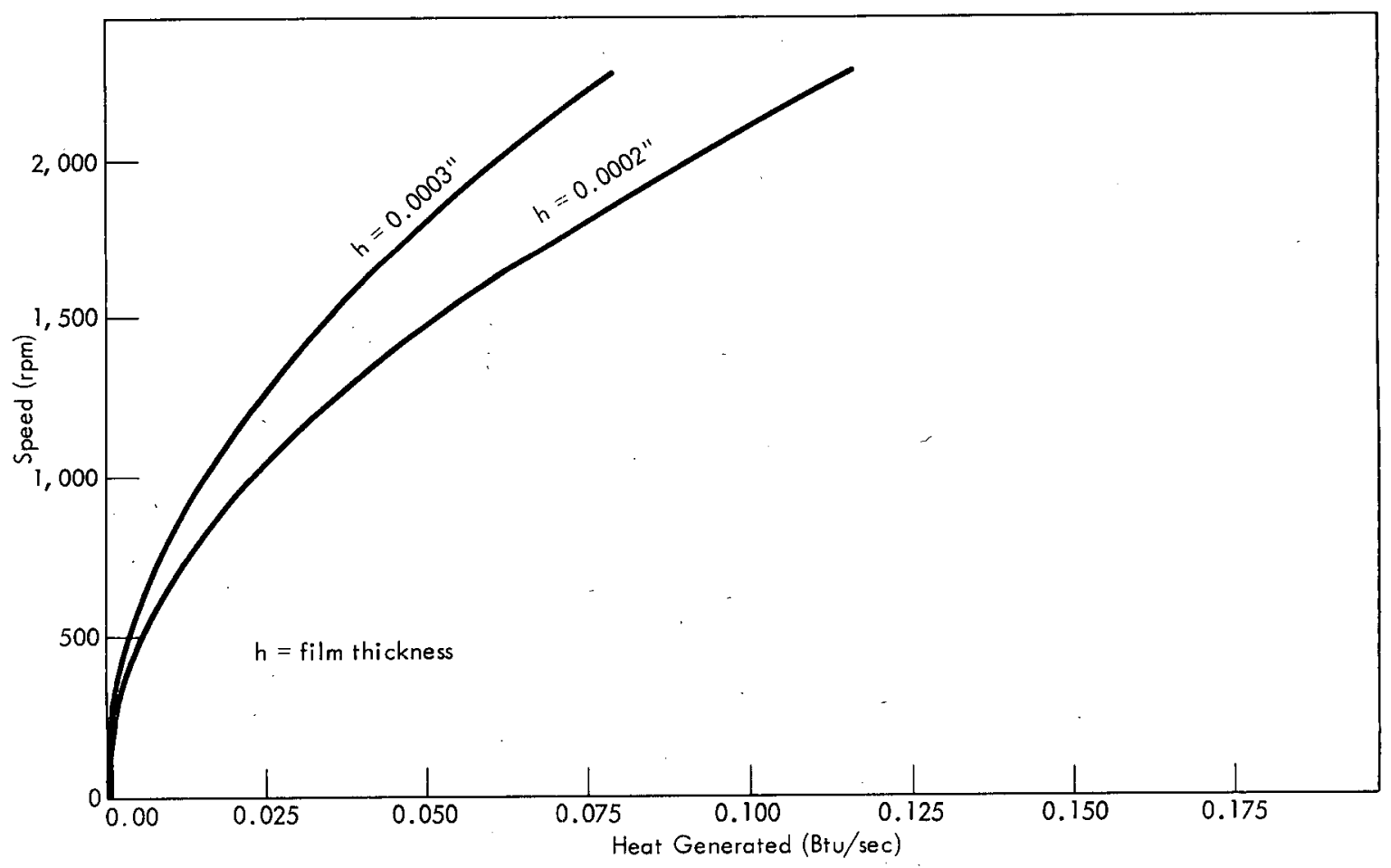

Figure 8. HEAT GENERATED IN THRUST BEARINGS. 
In calculating the bearing temperature rise, uniform temperature distribution in the housing and shaft was assumed. It was felt that this was a reasonable assumption under steady-state operating conditions since the primary limitation to heat dissipation was convection and radiation from the shaft face andhousing to the surrounding atmosphere.

The heat dissipation equations used were:

for absorption -

$$
Q_{\text {absorp }}=M C_{p}\left(t_{g_{2}}-t_{g_{1}}\right),
$$

for convection -

$$
Q_{\text {conv }}=h_{c} A\left(t_{s}-t_{r}\right),
$$

for radiation -

$$
Q_{\text {rad }}=\sigma F_{e} F_{a} A\left(t_{s}^{4}-t_{r}^{4}\right) \text {, and }
$$

for heat balance for the spindle -

$$
Q_{\text {gen }}=Q_{\text {absorp }}+Q_{\text {conv }}+Q_{\text {rad }}
$$

where:

A represents the surface area in square inches,

$Q$ the heat in Btu's per second,

$t_{s}$ the average spindle temperature in ${ }^{\circ} R$,

$t_{r}$ the average room temperature in ${ }^{\circ} R$,

${ }^{\mathrm{g}_{1}}$ the temperature of the exiting gas in ${ }^{\circ} \mathrm{F}$,

${ }^{t} g_{2}$ the temperature of the entering gas in ${ }^{\circ} \mathrm{F}$,

$C_{p}$ the specific heat in Btu's per $\mathrm{ft}^{3} \mathrm{-}^{\circ} \mathrm{F}$,

$M$ the volumetric rate of gas flow in $\mathrm{ft}^{3}$ per second,

$h_{c}$ the surface film coefficient of heat transfer in Btu's $/ \sec ^{-i n}{ }^{2}{ }^{\circ} \mathrm{F}$, 
$\sigma$ the Stefan-Boltzman constant which has a value of $0.334 \times 10^{-14} \mathrm{Btu} /$ in $^{2}-$ sec- $^{\circ}$ R4,

$F_{e}$ the emissivity factor, and

$F_{a}$ the shape and relative position factor.

The calculated values appear in graphic form in Figure 9. The surface film coefficient of heat transfer $\left(h_{c}\right)$ was that as recommended by King and Knaus, as reported by Brown and Marco, (5) for the flow of atmospheric air at $70^{\circ} \mathrm{F}$ over smooth plane surfaces at low velocities (less than $15 \mathrm{ft} / \mathrm{sec}$ ).

Volumetric gas flow rate through the bearings was predicted from an equation derived from Euler's equation for steady, one-dimensional flow with friction, neglecting the body force of weight and inertia for compressible fluid flow through a slot.

The derived equation used was:

$$
Q=\frac{b h^{3}}{24 \mu l_{s} P_{a}}\left(P_{o}^{2}-P_{a}^{2}\right)
$$

This equation will closely approximate flow, $Q\left(\mathrm{in}^{3} / \mathrm{sec}\right)$, out of a recessed bearing of perimeter, b (inches); film thickness, $h$ (inches), effective slot length, $I_{s}$ (inches), film pressure, $P_{0}$ (psia), and ambient pressure, $P_{a}$ (psia), for a fluid viscosity, $\mu($ lbs-sec/in 2$)$.

Although the bearings used in this spindle are not recessed, the air injection over the entire area of the pad yields a relatively flat pressure profile quite comparable to that of a recessedpad for which the slot-flow equation gives good agreement with the measured data. The same equation can be used satisfactorily for the porous bearings by using an effective slot length, as shown in Figure 10. These values were derived from an analysis of the pressure-distribution data obtained from the test pad used to determine bearing film stiffness. Good agreement with the measured flow through the spindle bearings was obtained.

Another set of temperature-rise calculations, presented in Figure 11, was made based on the measured temperature rise of an experimental air spindle similar to the one designed but considerably smaller in size. The results were derived by ratioing the bearing heat-generation and heat-dissipation areas in both cases. The heat generated in the bearing was based on theoretical calculations. Bearing friction measurements made on the experimental spindle indicated that the theoretical equations used were accurate within experimental limits. 


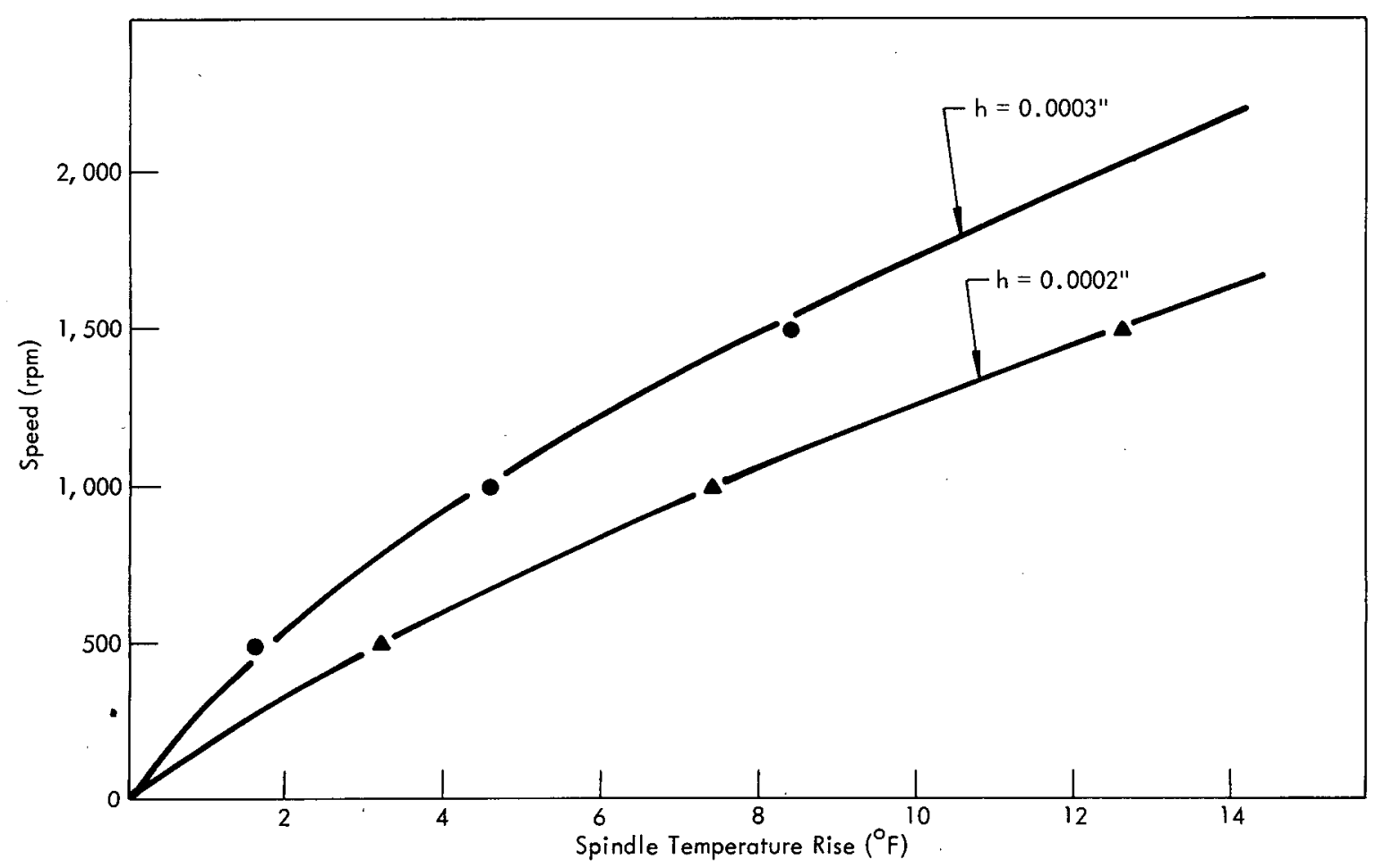

Figure 9. CALCULATED AIR-SPINDLE TEMPERATURE RISE.

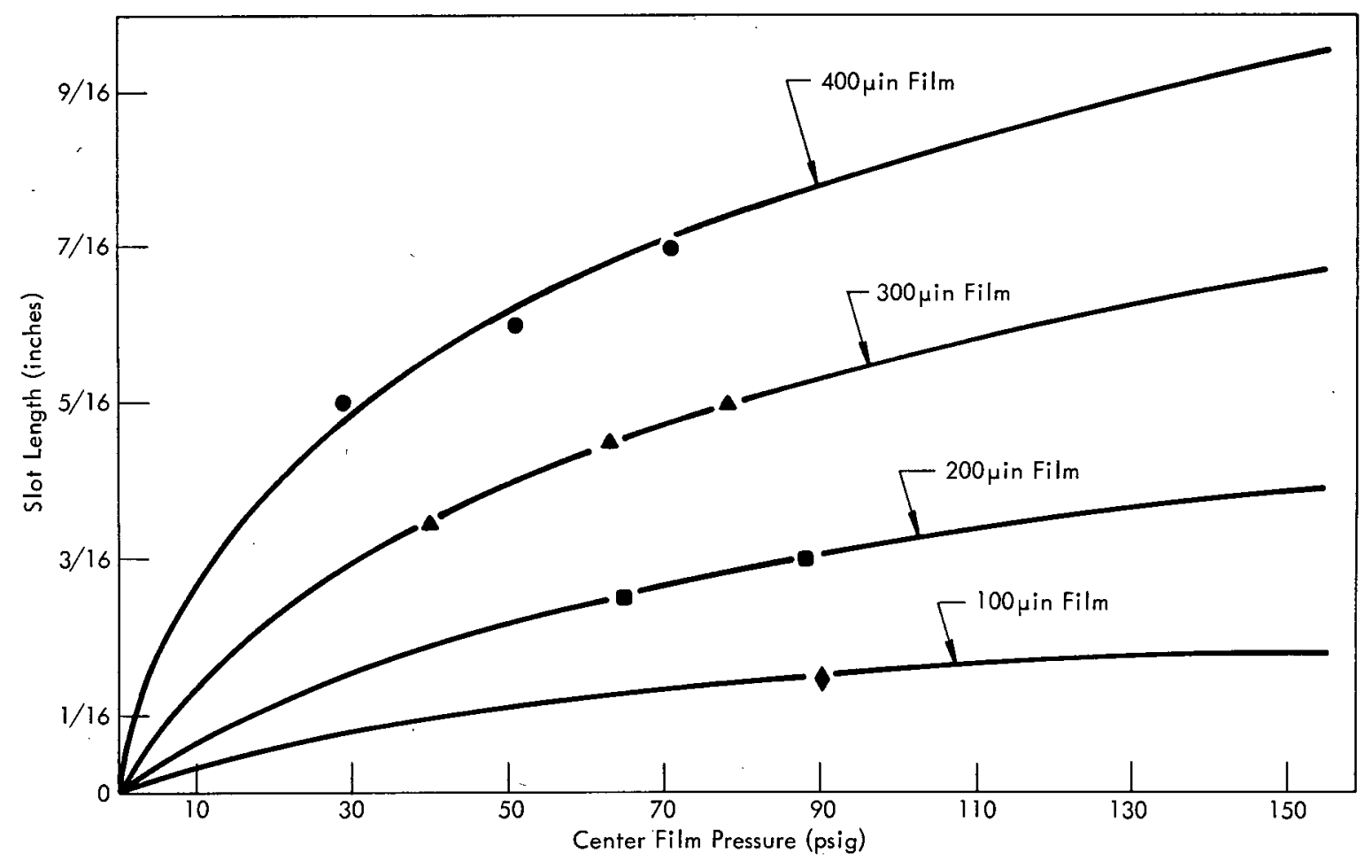

Figure 10. SLOT LENGTH FOR SLOT FLOW APPROXIMATION. 


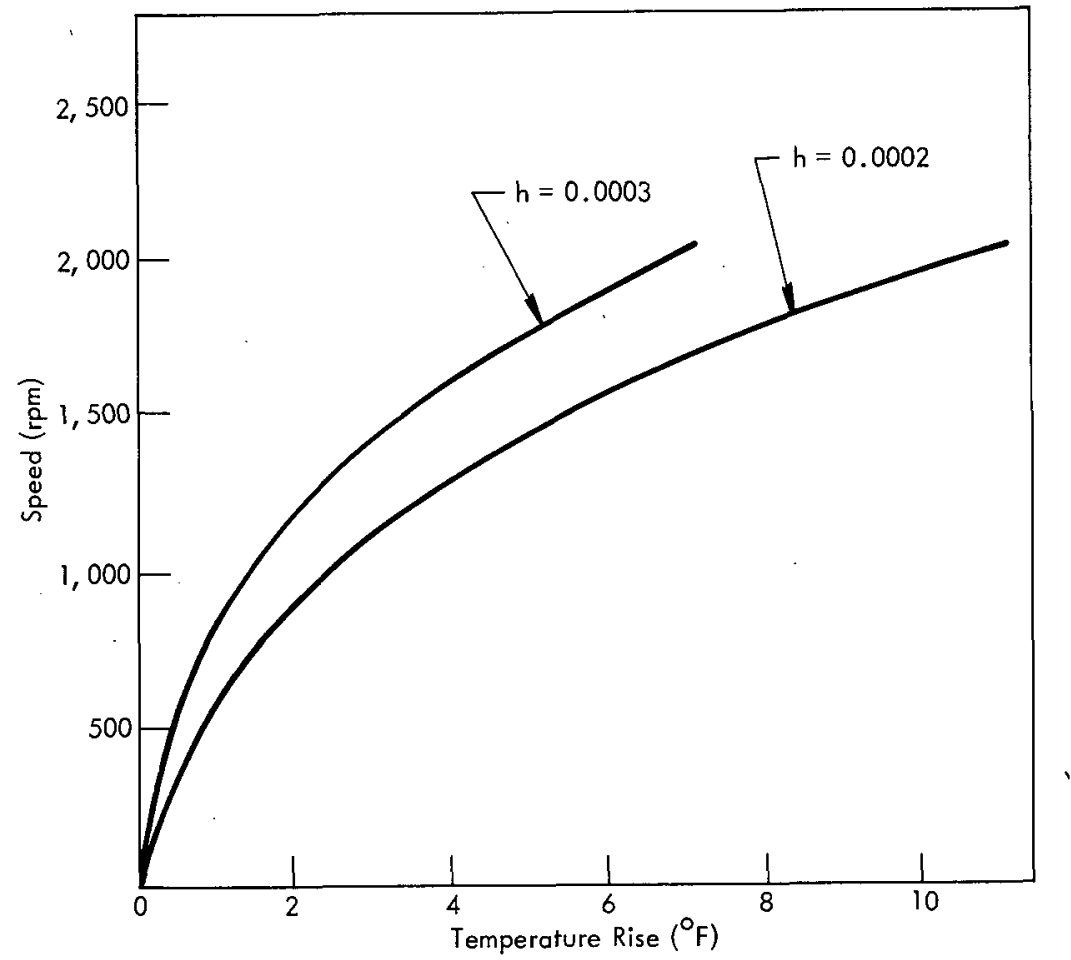

Figure 11. SPINDLE TEMPERATURE RISE BASED ON MEASURE. MENTS TAKEN FROM A SMALL, EXPERIMENTAL AIR SPINDLE. (Refer to Figure 9)

Temperature rise predicted by this method is less than that calculated. At 1,000 rpm, the latter method predicts $2^{\circ} \mathrm{F}$ while the former method indicates a temperature rise of $4.5^{\circ} \mathrm{F}$. The actual measured temperature rise that was obtained at different locations in arriving at steady-state conditions, fell between the two values. Use of the former method gives a conservative value for design purposes.

\section{SPINDLE FABRICATION}

Construction details of the housing and journal-bearing pads are shown in Figure 2 and 12; the assembled thrust-bearing pad is shown in Figure 13. The porous Graphitar used in the thrust and journal-bearing pads was fastened to the bearing-pad housings, after machining, with. Epon 828 epoxy resin and TETA curing agent. Curing time for the epoxy was approximately three days at room temperature.

Because of the precision requirements of the spindle, it was necessary to lap the bearing components. The journal bearings required individual lapping to obtain roundness and paired lapping to obtain the desired radius difference. The thrust bearings required lapping to obtain a flat surface. Design of the spindle laps, shown in Figures 14 and 15, was based on information resulting from the work done at Du Pont by T. G. Lewis. (2) Conventional cylindrical laps are usually made adjustable by splitting the lap along a line parallel to the axis of the cylinder. However, 


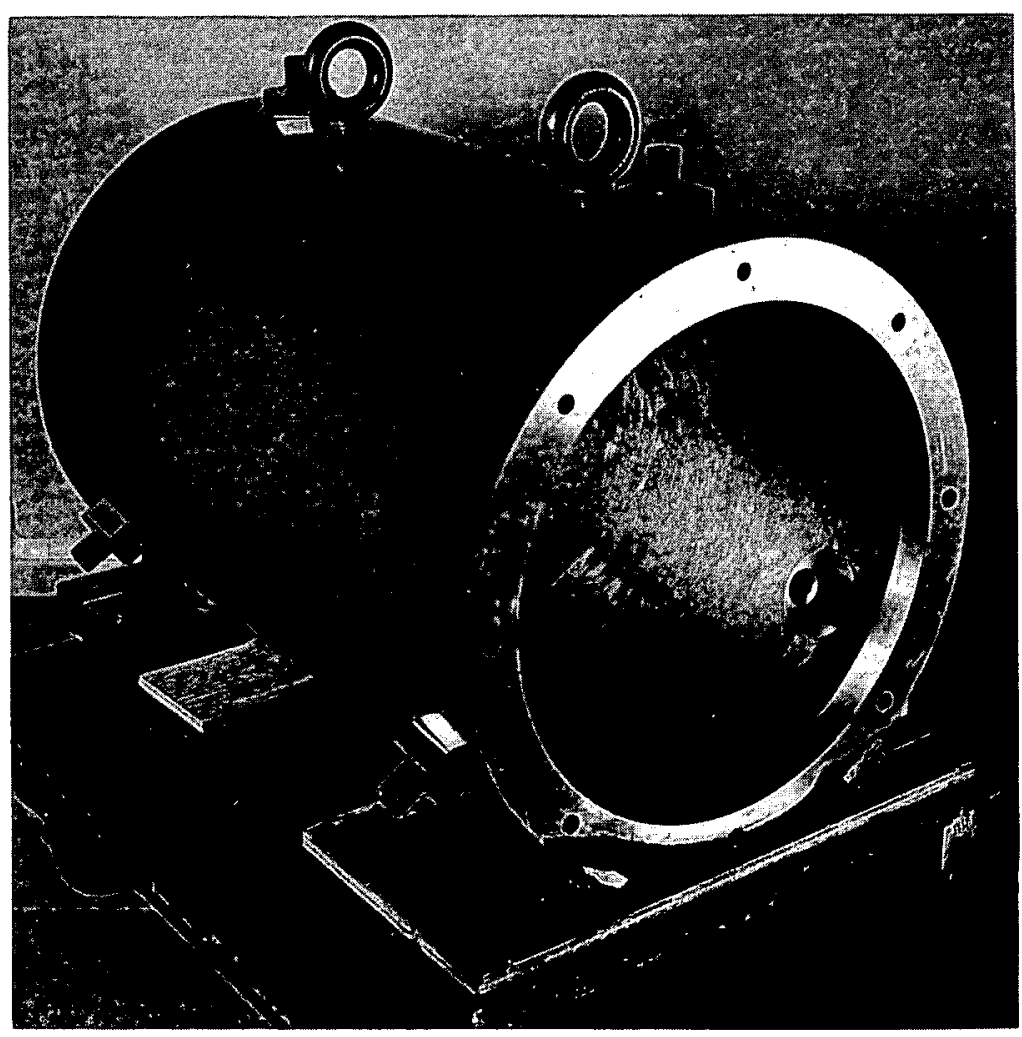

114827

Figure 12. AIR-BEARING SPINDLE HOUSING.

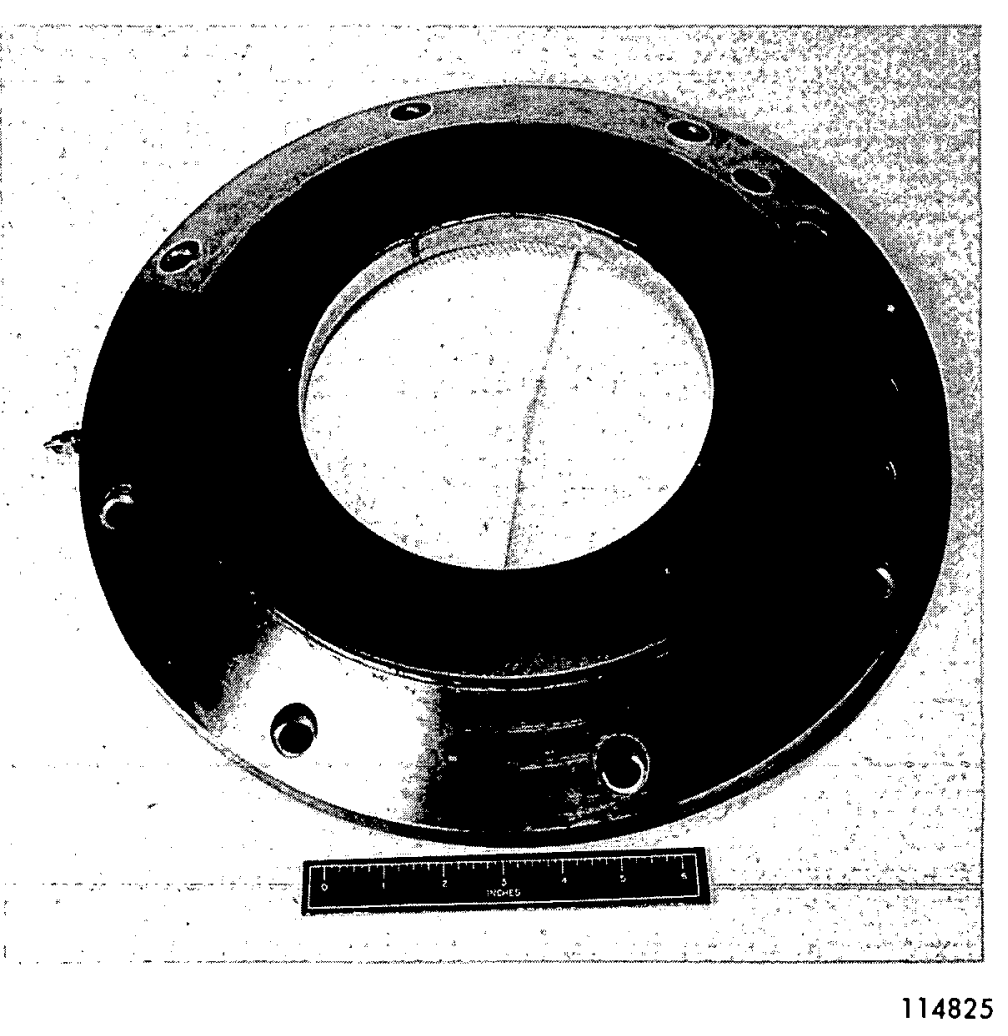

Figure 13. ASSEMBLED AIR BEARING THRUST-BEARING PAD. 


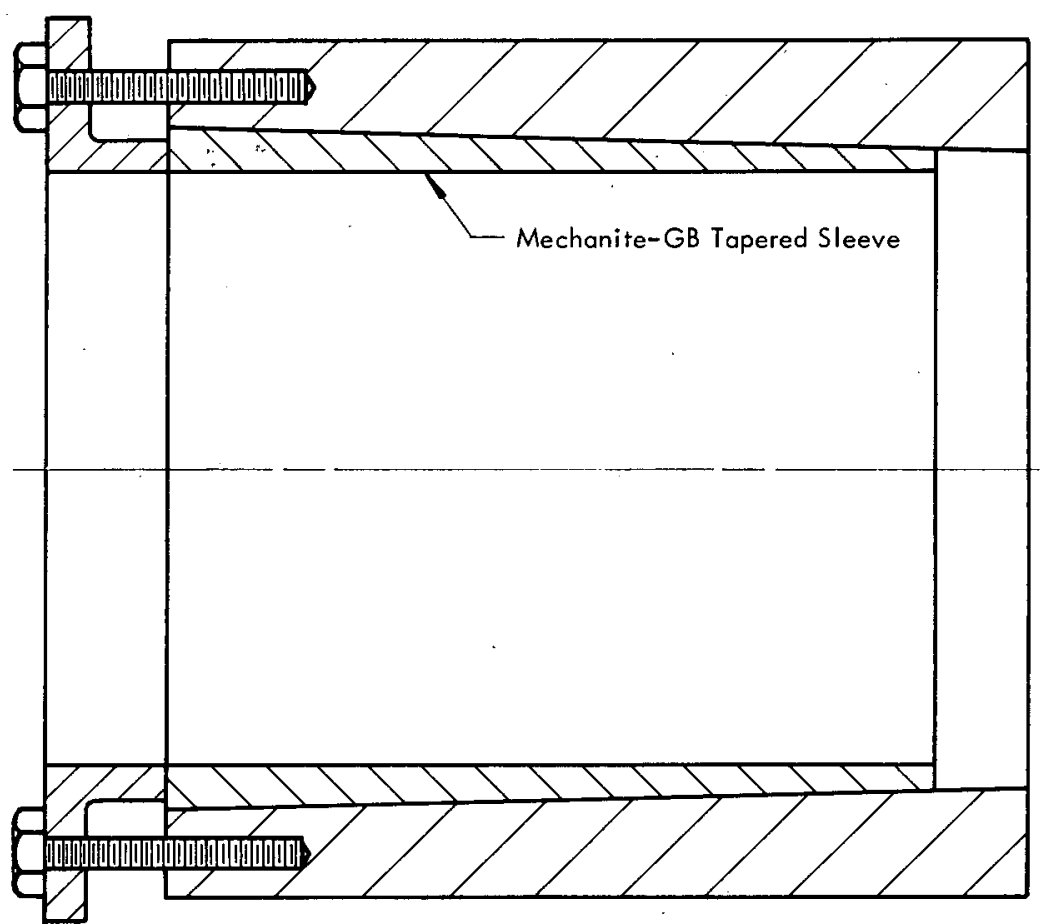

Figure 14. AIR-SPINDLE JOURNAL LAP.

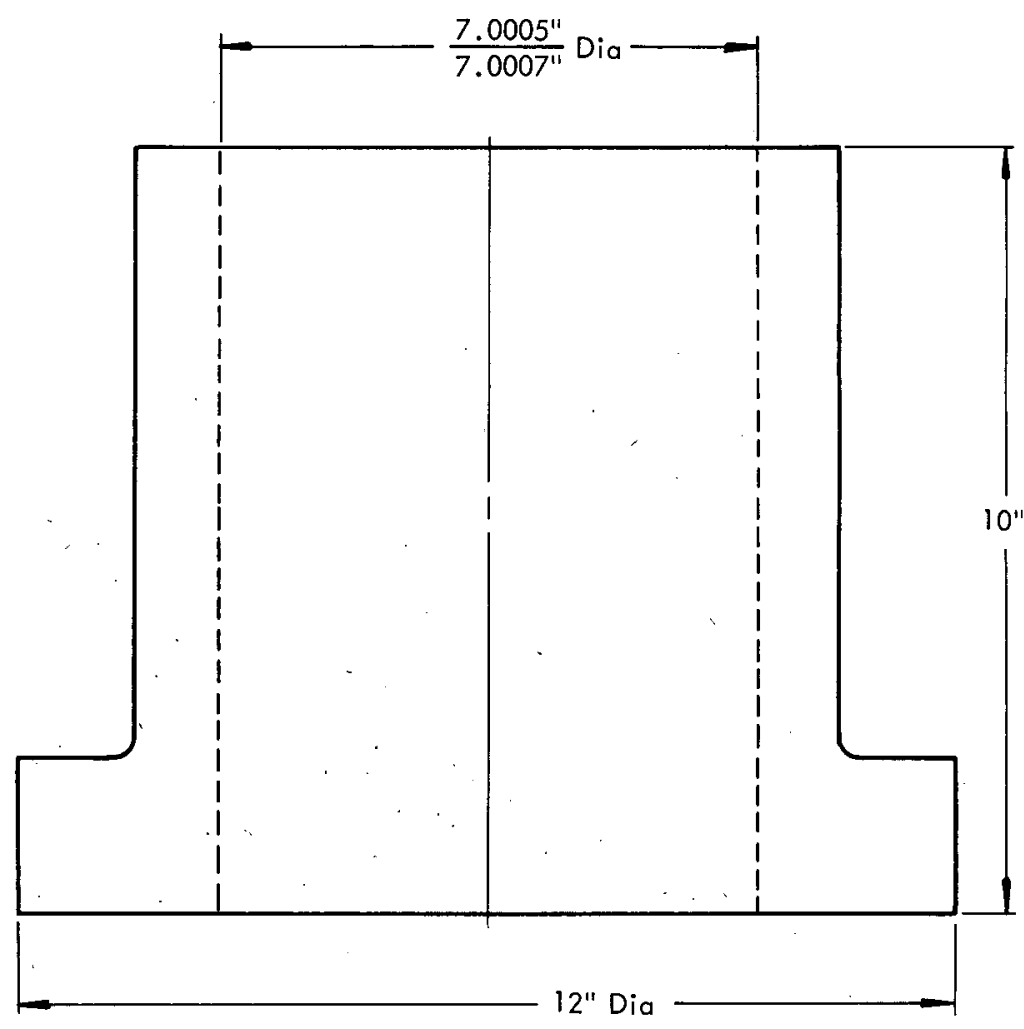

Figure 15. THRUST LAP. 
experience indicated that this method of diameter adjustment would be unsuitable for precision applications because the splits reduce the lap stiffness. The cylindrical lap shown was designed to permit adjustment while retaining maximum stiffness. Adjustment is made by moving the tapered Meehanite-GB cast iron sleeve axially within the holder by means of the pull-down ring. This operation compresses the sleeve and reduces the inside diameter. The assembled journal lap is shown in Figure 16. The thrust lap, shown in Figure 15, was used to lap the front-thrust runner on the shaft. The lap was rotated about the front journal with a film of molybdenum disulfide grease between them. The face of the lap was kept flat by occasional lapping on a 4-inch-thick by 36-inch-diameter cast iron plate. This plate was also used to lap all the other flat thrust-bearing components.

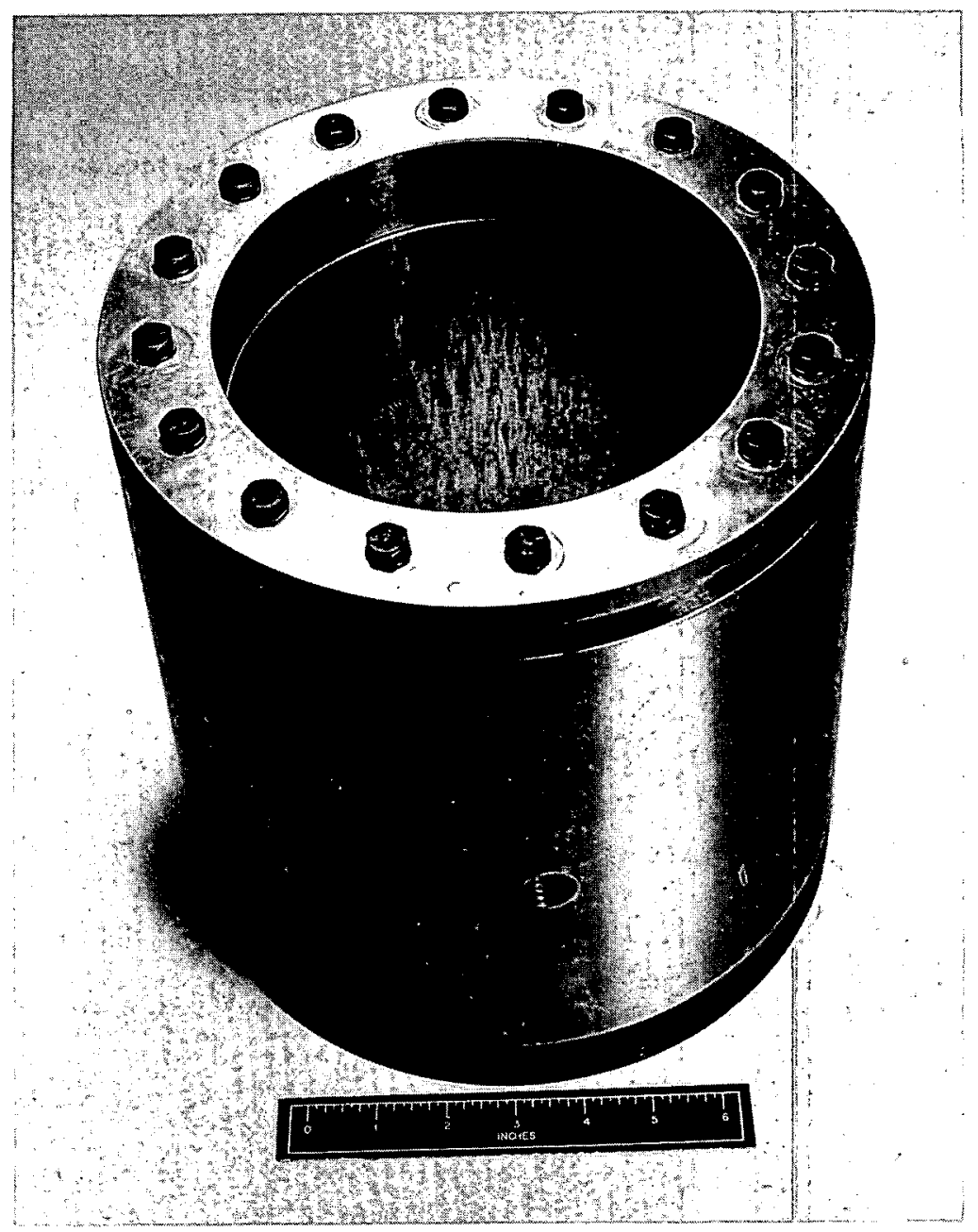

Figure 16. ASSEMBLED JOURNAL LAP. 
The graphite bearings were lapped after grinding with successive grades of compound. The grades used were fifteen, nine, and six-micron aluminum oxide or diamond compound. Initial lapping in each case was done with the compound wetted with ethyl alcohol. The final lapping was dry, but alcohol was used to spread the compound. The metal bearing surfaces were lapped using the same grades of compound mixed with a light oil. Oil was not used when lapping the graphite because of the difficulty involved in removing oil from graphite. Oil left in the graphite will adversely affect the bearing performance. After lapping, the surfaces were thoroughly cleaned with trichloroethylene. The graphite was pressurized during cleaning to remove particles pushed into the pores of the material and to keep the solvent from coming in contact with the epoxy bond, since prolonged exposure to the solvent will soften the epoxy.

Final fitting of the journal bearings was done by lapping them to their respective shaft journal. To obtain proper tension of the bearings during lapping along the journal length, differential screws were inserted between the two shoes left unconnected in the spindle assembly, as shown in Figure 17. With these screws, incre-

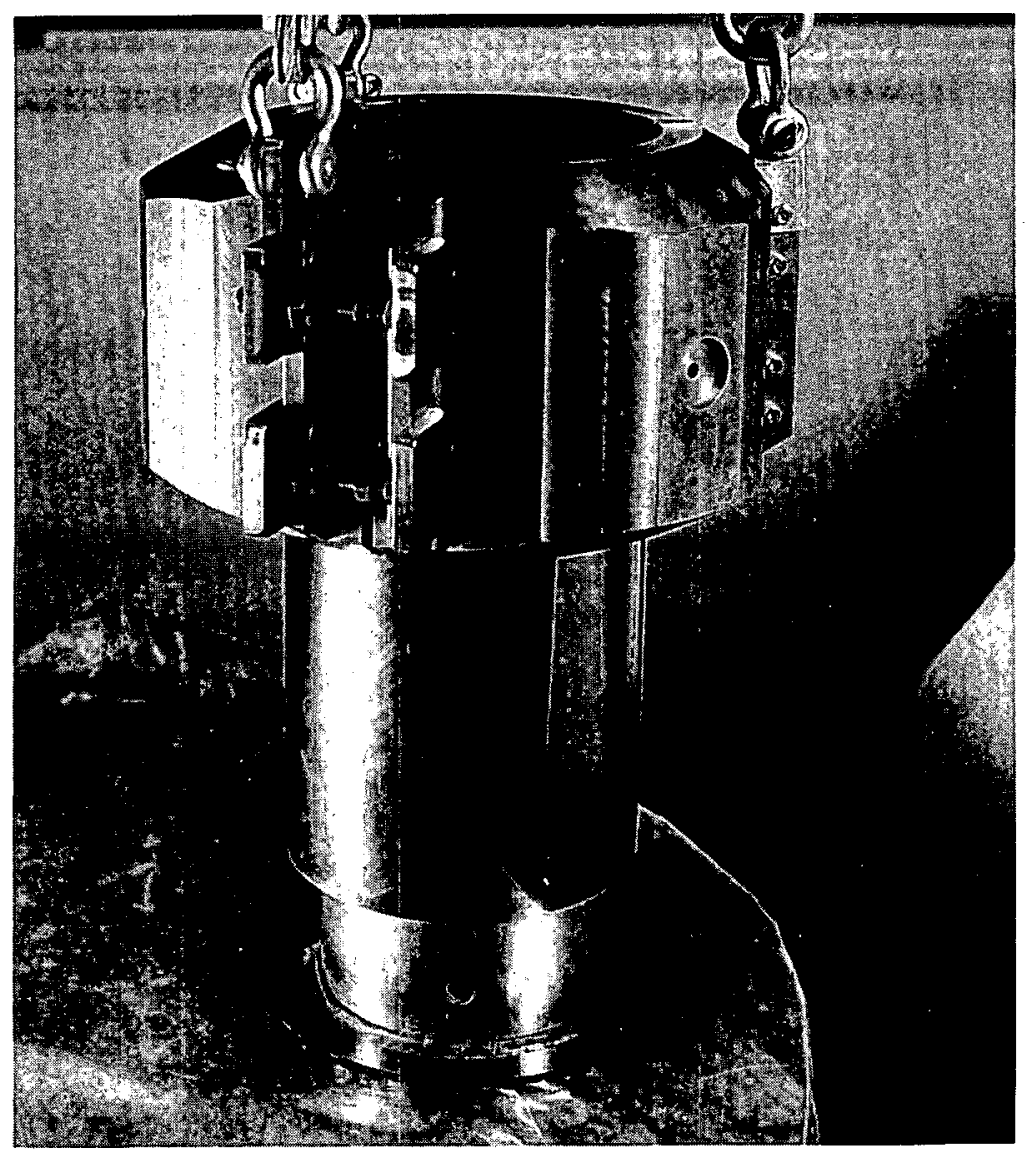

114665

Figure 17. ARR ANGEMENT FOR LAPPING THE JOURNAL BEARING PAD ASSEMBLY. 
mented changes in the bearing diameter of approximately 50 microinches were made to adjust the clearance left by the bearing-material removal.

Dry compound with a particle size of six microns was used for this operation. The size of this compound and some clearance required to move the bearing assembly gave a pad radius approximately 300 microinches larger than the journal radius, which was the desired clearance for spindle operation. After final lapping of the shaft journals and bearings, roundness measurements indicated journal roundness of 12 - 15 microinches TIR. Concentricity of the journals was measured before lapping and was found to be better than 25 microinches. This condition improved slightly. The rear thrust runner was lapped flat radially within five microinches and flat circumferentially with in 20 microinches. The front thrust runner was flat radially within 10 microinches and circumferentially within 30 microinches. Surface finish of the journals was less than one microinch. The finished shaft is shown in Figure 18. If better concentricity of the journals is desired than that obtained for this shaft, or if the initial grinding of the shaft exceeds the required concentricity, it will be necessary to localize journal lapping to improve this condition. Geometrical evaluation of the journals can be made using the setup presented in Figure 19. Two of the three bearing shoes are located on a surface plate spaced for each journal surface of the shaft. Air is supplied at about 15 psi to each shoe through the spherical seats in the same way as that in the assembled spindle. This pressure supports the shaft for rotation. A "toolmaker's knee" is placed on the surface plate with the face of the knee oriented at a position normal to the axis of the spindle. The surface plate is adjusted with about a $1 / 2$ to 1-degree tilt, with the front thrust end of the shaft on the high side of the plate. A precision steel ball with a $3 / 8$ to $1 / 2$-inch diameter is placed between the conical center left in the spindle from the turning and guiding operations and the toolmaker's knee. When air is supplied to the shoes, gravitational force causes the spindle to float toward the knee. The ball makes point contact with the face of the knee. This arrangement provides a thrust bearing for testing during the lapping operations.

Geometrical evaluation of the journal-bearing surfaces consists of positioning an electronic displacement indicator, or its equivalent, at top dead center at one end of one of the journal-bearing surfaces. A reference mark is placed on the periphery of the nose of the spindle to establish the angular position of all data to be taken. The spindle is then slowly turned by hand at about $1 / 2$ to 1 revolution/second. The runout of the surface is as indicated by the displacement indicator, and a polar plot is recorded for the axial position. Similar plots are recorded for the opposite end of the journal surface, as well as for both ends of the other journal surface.

If a plot is taken at the axial center of each journal surface, the surfaces generally show smaller deviations; however, the self-aligning feature of the design makes each journal surface rotate about a point at the axial center of the surface. The deviations recorded at this position are entirely those caused by out of roundness, 


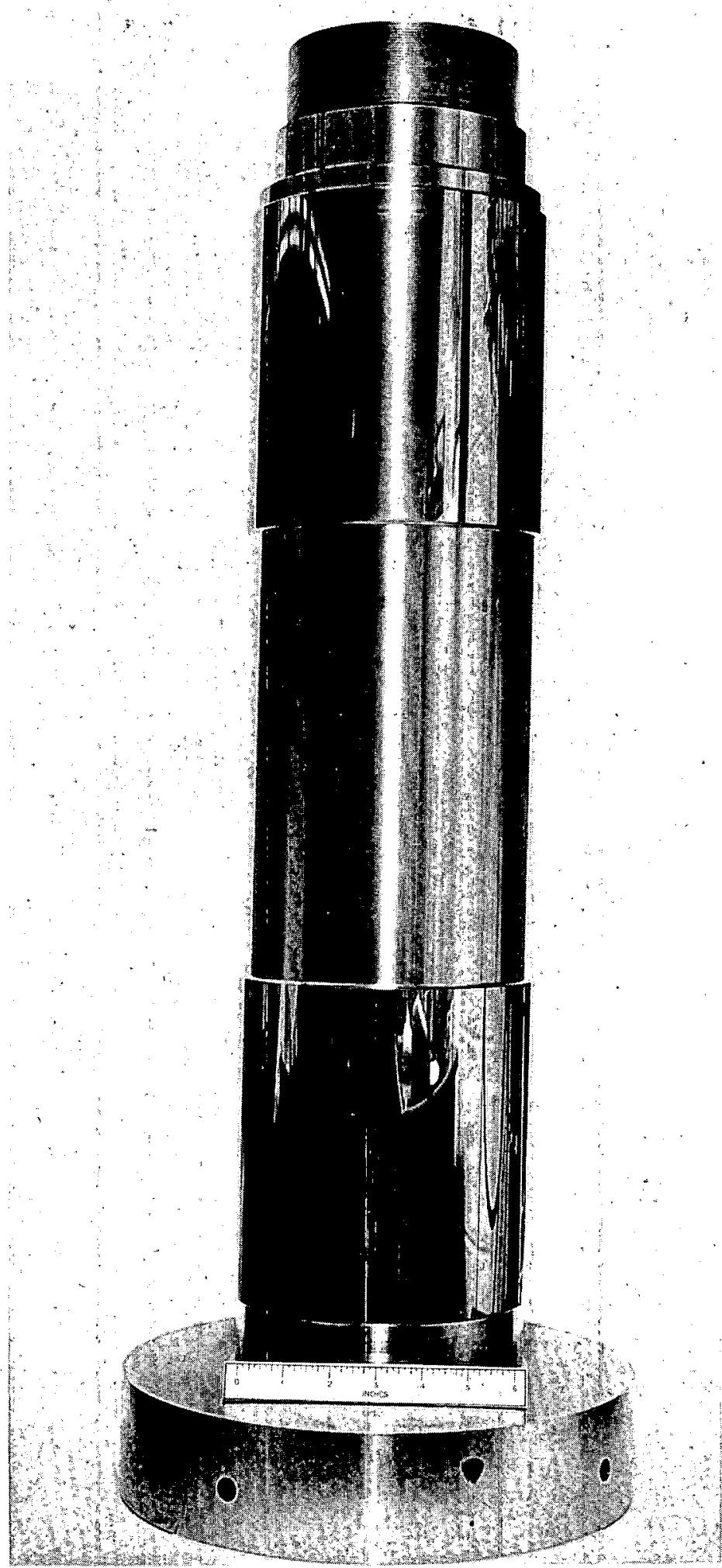

Figure 18. FINISHED AIR-BEARING SHAFT. 
while those recorded at the ends of the journal surfaces result from out of roundness and whatever "crank motion" that may exist. The objective of all subsequent lapping is to remove all of this crank motion and, at the same time, make the cylindrical surface truly round.

A study of the polar plots will indicate the direction of the crank motions in each journal surface, and it will be obvious where metal must be removed to eliminate it. Localized lapping is performed which leads to a somewhat oval condition at that axial position. The subsequent application of the cylindrical lap, however, will bring the surface back toward a true cylinder. Thus, by displacement indicating,

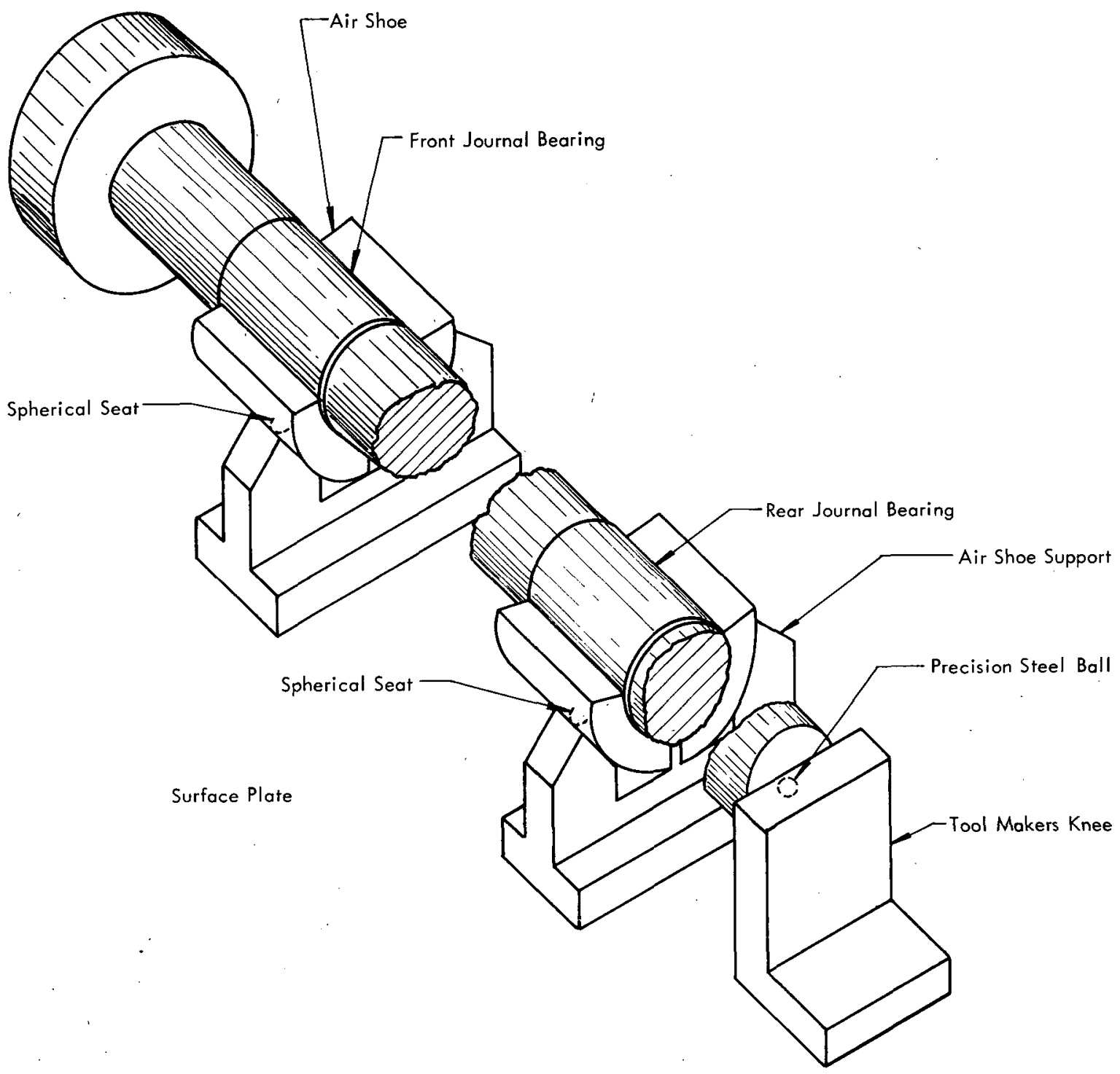

Figure 19. SPINDLE TEST RIG. 
plotting, localized lapping, and full cylindrical lapping, a condition is reached where the indicated errors can be reduced to that desired. Generally, an accuracy that is two to three times better will be obtained with the assembled spindle over the previous measurement due to the restoring force of the hydrostatic film.

\section{SPINDLE ASSEMBLY}

Assembly of the spindle was done in the vertical plane. With the shaft upright, the front thrust-bearing pad and front-journal bearing-pad assembly were set in place. Thermocouple wires, pressure tap tubing, and the connecting cable of a linear variable differential transducer (LVDT) mounted in the journal-pad assembly for measuring film thickness were taken out through exhaust ports in the front thrustbearing pads. The housing was then lowered over the subassembly and the differential screws and spherical seats installed to support the front journal-pad assembly in its proper position. The rear journal pad and thrust assembly were then set in place and secured with the differential screws and lock nuts. With the shaft clamped securely by the bearing pads, the spindle wasplaced in the horizontal position. The assembled air-bearing spindle is shown in Figure 20.

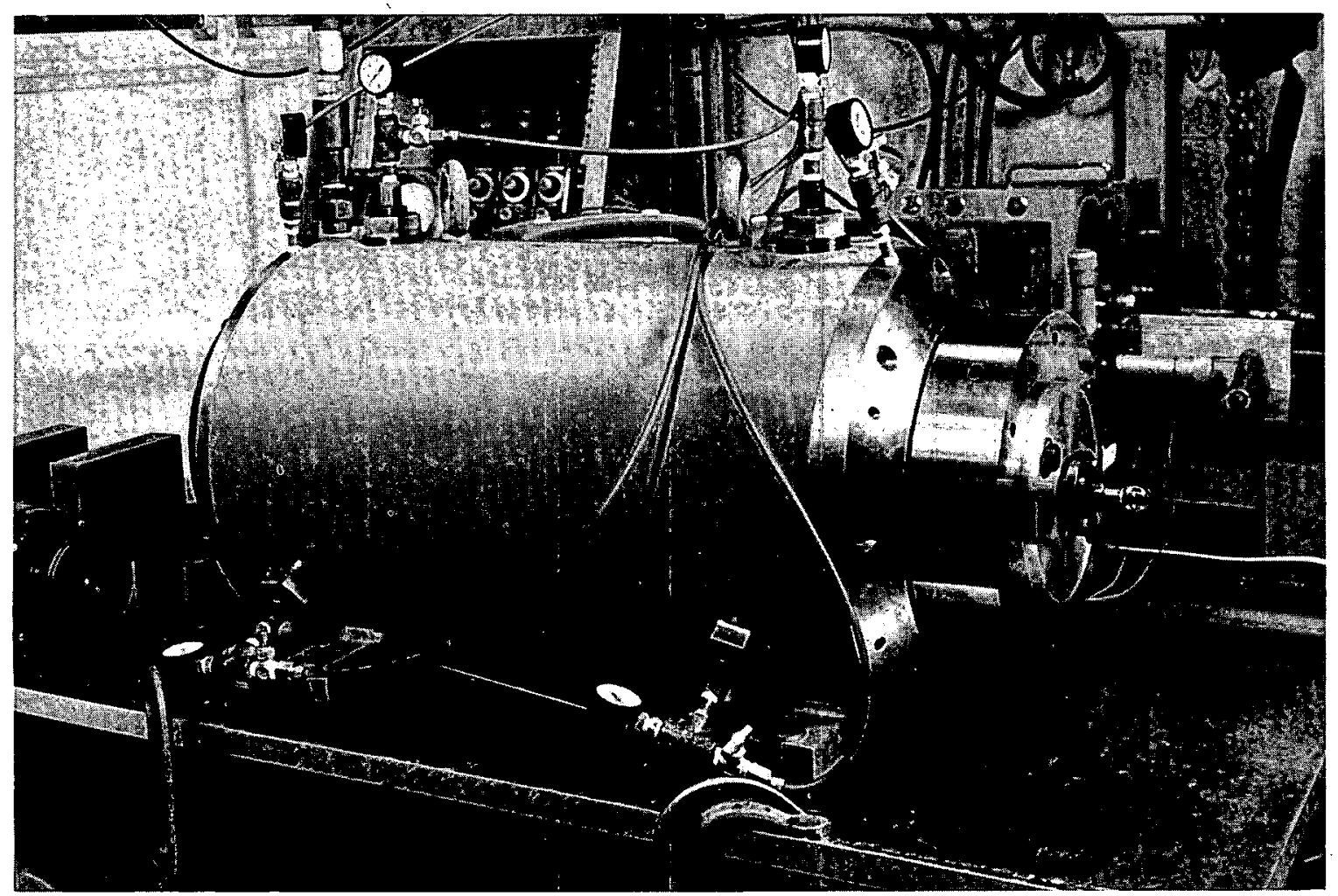

Figure 20. ASSEMBLED AIR-BEARING SPINDLE. 
To measure radial film thickness, an LVDT was mounted in the pad assembly in such a manner as to measure circumferential changes of the assembly. The ratio of the circumferential change at the point of LVDT installation to the change in the inside diameter was determined by testing the system on the shaft before assembly. The overall ratio of circumferential change at the point of LVDT installation to the film thickness change is ten to one. Thus, a movement of one mil of the LVDT, as arranged, indicates a change in film thickness of $0.1 \mathrm{mil}$.

In aligning the spindle, the shaft was roughly centered radially in the housing with the radial pads. Next, variations in the front thrust gap were observed from light penetration between the front thrust-runner face and the bearing pad. The shaft was then shifted until light could nolonger be seen through the gap. A mirror wasplaced on the face of the shaft and an autocollimator arranged to read the angular deviations that occurred when pressurizing the thrust film. The shaft was shifted with the rear journal pads until the angular deviations were minimized. The rear thrust-runner unit was removed and the thrust pad shimmed until it was perpendicular within $0.1 \mathrm{mil}$ to the axis of rotation, then the rear thrust was reassembled.

\section{SPINDLE EVALUATION}

The performance characteristics of the spindle were determined by using an instrument air supply to the spindle of 200 psig and indicated bearing pressures of 110 psig at the journals and 100 psig at the thrust bearings. The nominal film thicknesses were 270 microinches for the journals, 300 microinches at the front thrust, and 250 microinches at the rear thrust. Supply pressure to the filters was 220 psig. Air flow to the journal bearing for this condition was $6.6 \mathrm{scfm}$ for the journal bearings and $6.0 \mathrm{scfm}$ for the thrust bearing. The flow for the journals is slightly less than that predicted from experimental flow data for the stated film thickness; the thrust flow is about 50 percent higher. The higher thrust flow is attributed to unevenness of the thrust-bearing films which has an insignificant effect on the accuracy of the spindle.

The dry instrument air supply was filtered by a 0.15 micron filter in series with a standard 5-micron fluid filter. Measurements of the filtered air with a particle counter indicated that the air contained no particles above $0.5 \mathrm{micron}$. This degree of filtration is required to prevent the graphite material from plugging since about 80 percent of the graphite pore diameters fall in the range of 1.5 to 3.0 microns.

\section{Stiffness}

The spindle static deflection rate was measured at a point six inches in front of the spindle face. The load was applied at the spindle face but increased by an amount equal to the ratio of the lengths from the point of measurement to the point of application from the center of the front journal bearing. Since film deflection is low, this action effectively placed the load at the point of deflection measurement. The 
radial deflection rate measured was 1.12 microinches per pound; the axial deflection rate was $0.05 \mathrm{microinch}$ per pound. These values which are less than the specified deflection rates agree well with the rates predicted by a design of 0.90 microinch per pound radially and 0.05 microinch per pound axially, using the single-beam approximation. The test used to measure the radial deflection rate is shown in Figure 21. A Dillon force gage(a) was used to measure the applied force. Deflection was measured with a Dynagage, Model DG-400.(b) The deflection was approximately linear for loads up to 400 pounds.

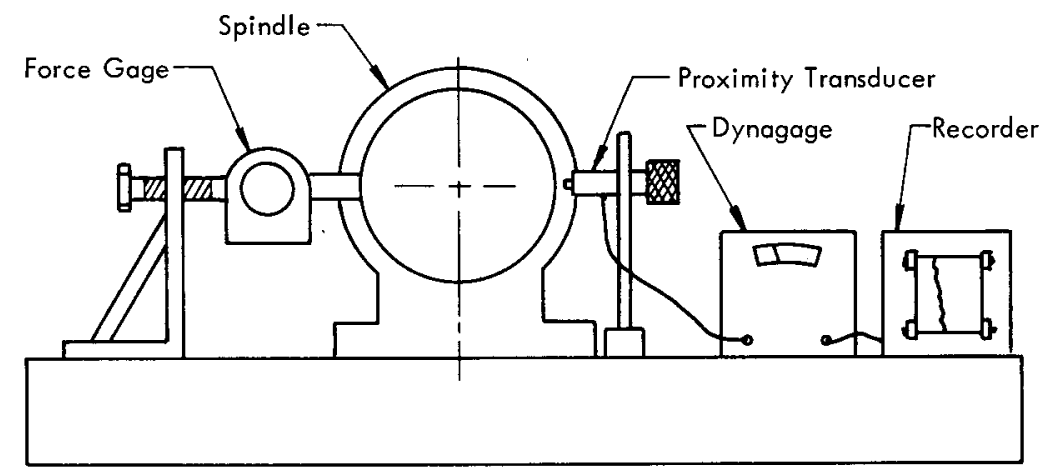

Figure 21. TEST EQUIPMENT ARRANGEMENT FOR DEFLECTION MEASUREMENTS.

Rotational Accuracy

Radial runout measurements of the spindle were made using a two-microinch TIR hemispherical standard mounted 20 to 30 microinches off center on the spindle, and two Dynagages, Model DG-400. The proximity transducers were set at right angles with each other with their outputs displayed after filtering at different levels with Kron-Hite Model 335 filters, (c) in the form of a Lissajous pattern on a Type 546 Textronic (d) storage oscilloscope. With a perfect standard, zero runout of the spindle would appear as a true circle on the oscilloscope whose radius is a measure of the misalignment of the standard's center of revolution and the spindle center of rotation. Deviation from a true circle is a measure of the combination of the standard and spindle runout and the inaccuracies of the measuring system. The measuring system, when properly calibrated, has a probable accuracy of \pm 10 percent of the range of measurement. The system arrangement is presented in Figure 22.

(a) Manufactured by W. C. Dillon and Company, Inc, Van Nuys, California.

(b) Manufactured by Photocan Research Products, Pasadena, California.

(c) Manufactured by Kron-Hite Filters, Cambridge, Massachusetts .

(d) Manufactured by Textronic, Inc, "Portland, Oregon. 


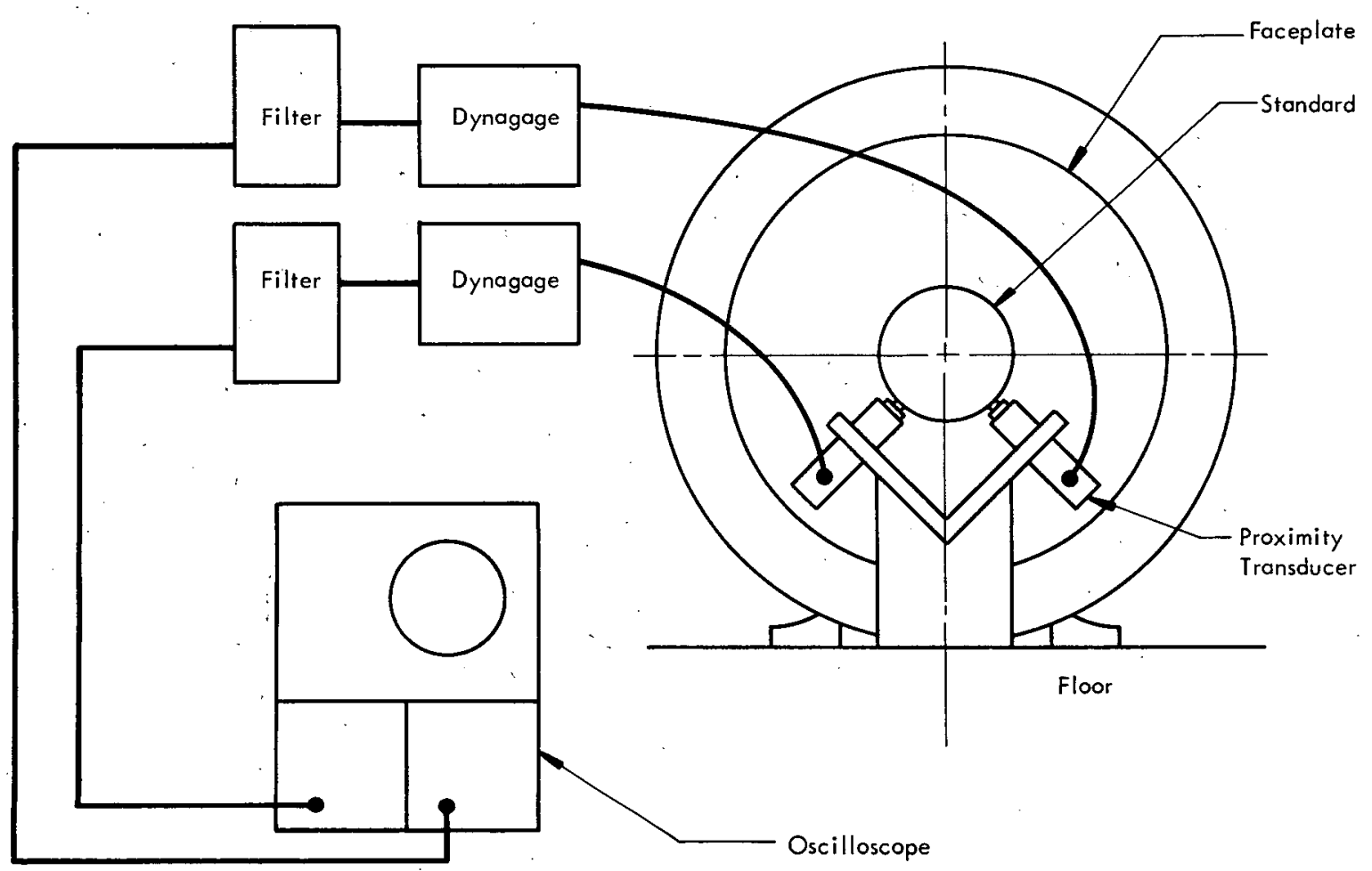

Figure 22. FRONT VIEW OF AIR SPINDLE SHOWING DYNAGAGE HEADS MOUNTED SOLID FROM THE FLOOR.

Rotational accuracy of the spindle was also measured indirectly from test specimens machined on the spindle with a diamond knife. The results obtained using the direct Dynagage method were 6-10 microinches radial runout and 4- 12 microinches axial runout from static to $1,500 \mathrm{rpm}$. The results obtained from the test specimens machined were $4-8$ microinches radial runout and $7-10$ microinches end camming from 500 to 1,500 rpm. The test-specimen configuration is presented in Figure 23; the results obtained from both methods are tabulated in Table 1. Figure 24 shows the Talyrond charts of the 1,500-rpm specimens. Photographs of typical Lissajous patterns obtained using the direct Dynagage measurement method are given in Figure 25. The test part during these tests was located approximately four inches in front of the spindle face. Angular deviation of the spindle was better than $1 / 2$ second of arc.

\section{Growth}

Measurements of the axial movement of the spindle face relative to the housing were made for various spindle loads at 1,000 and 2,000 rpm. During these tests the temperature rise of the bearing pads was measured at a point approximately $1 / 4-$ inch radial distance from the rotor on each end of the journal shoes and $1 / 4$-inch axial distance from the rotor on each thrust bearing. Iron/constantin thermocouples and a Leeds-Northrup potentiometer were used for this measurement. The thermocouples were placed 120 degrees apart radially around the bearings. The results of both tests are shown graphically in Figures 26 through 31 . Loads used at 1,000 rpm were 0, 


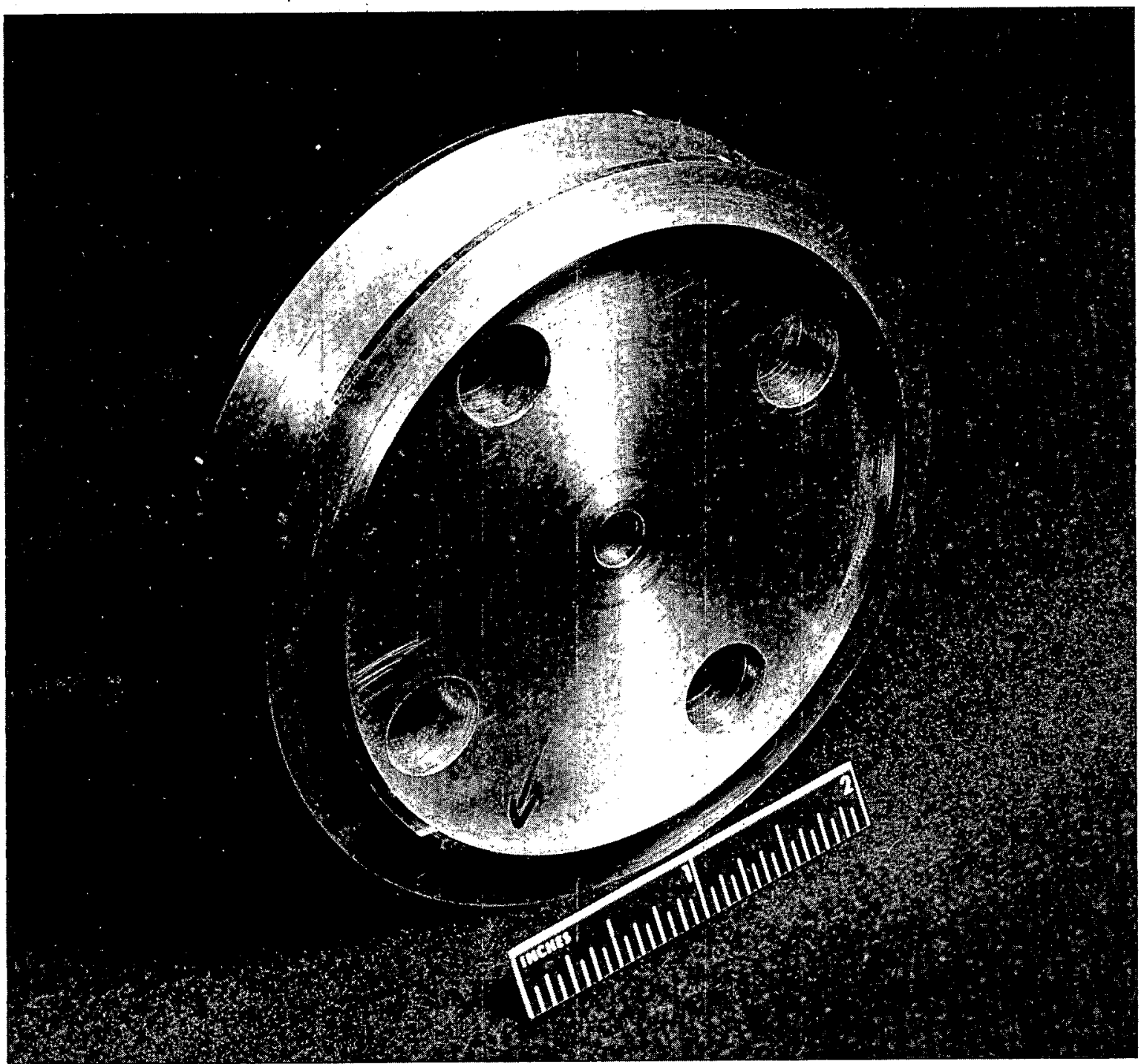

116600

Figure 23. TEST SPECIMEN MACHINED ON THE SPINDLE.

Table 1

SPINDLE ACCURACY MEASUREMENTS

\begin{tabular}{rccccc}
\hline \multicolumn{2}{c}{$\begin{array}{c}\text { Radial Runout } \\
(\mu \text { in TIR) }\end{array}$} & $\begin{array}{c}\text { Test } \\
\text { Specimen } \\
\text { Measurement }\end{array}$ & $\begin{array}{c}\text { Axial } \\
\text { Runout } \\
(\mu \text { in })\end{array}$ & $\begin{array}{c}\text { End } \\
\text { Camming } \\
(\mu \mathrm{in})\end{array}$ \\
\cline { 2 - 5 }$)$ & Dynagage & - & 4 & - \\
20 & 8 & 8 & - & 6 & 10 \\
500 & 10 & 4 & 9 & 7 \\
1,000 & 10 & 8 & 12 & 8 \\
1,500 & 8 & & & & \\
\hline
\end{tabular}

(1) Three-inch-diameter specimen. 

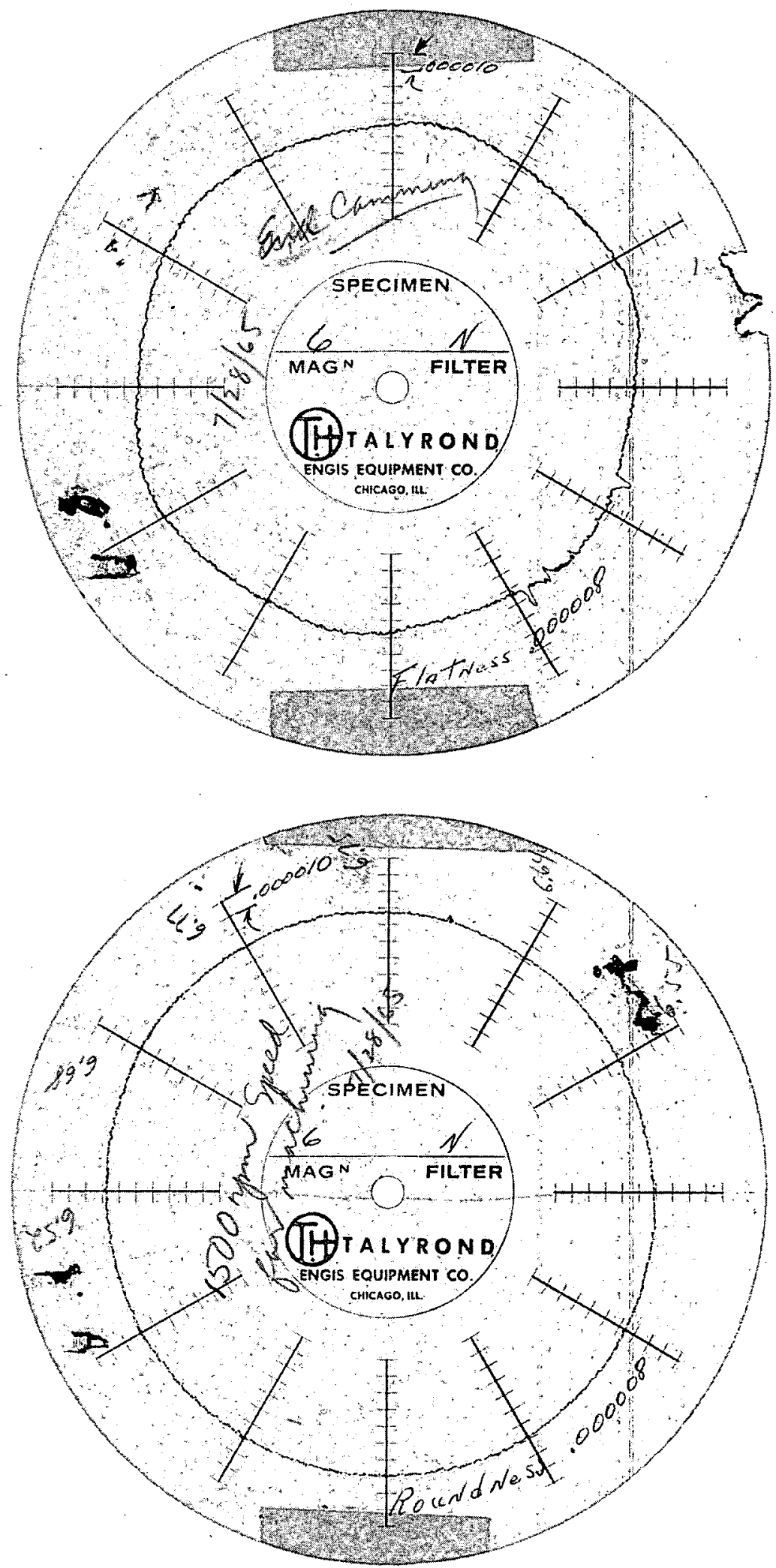

Figure 24. TALYROND CHARTS OF THE TEST SPECIMEN MACHINED AT 1,500 RPM. 

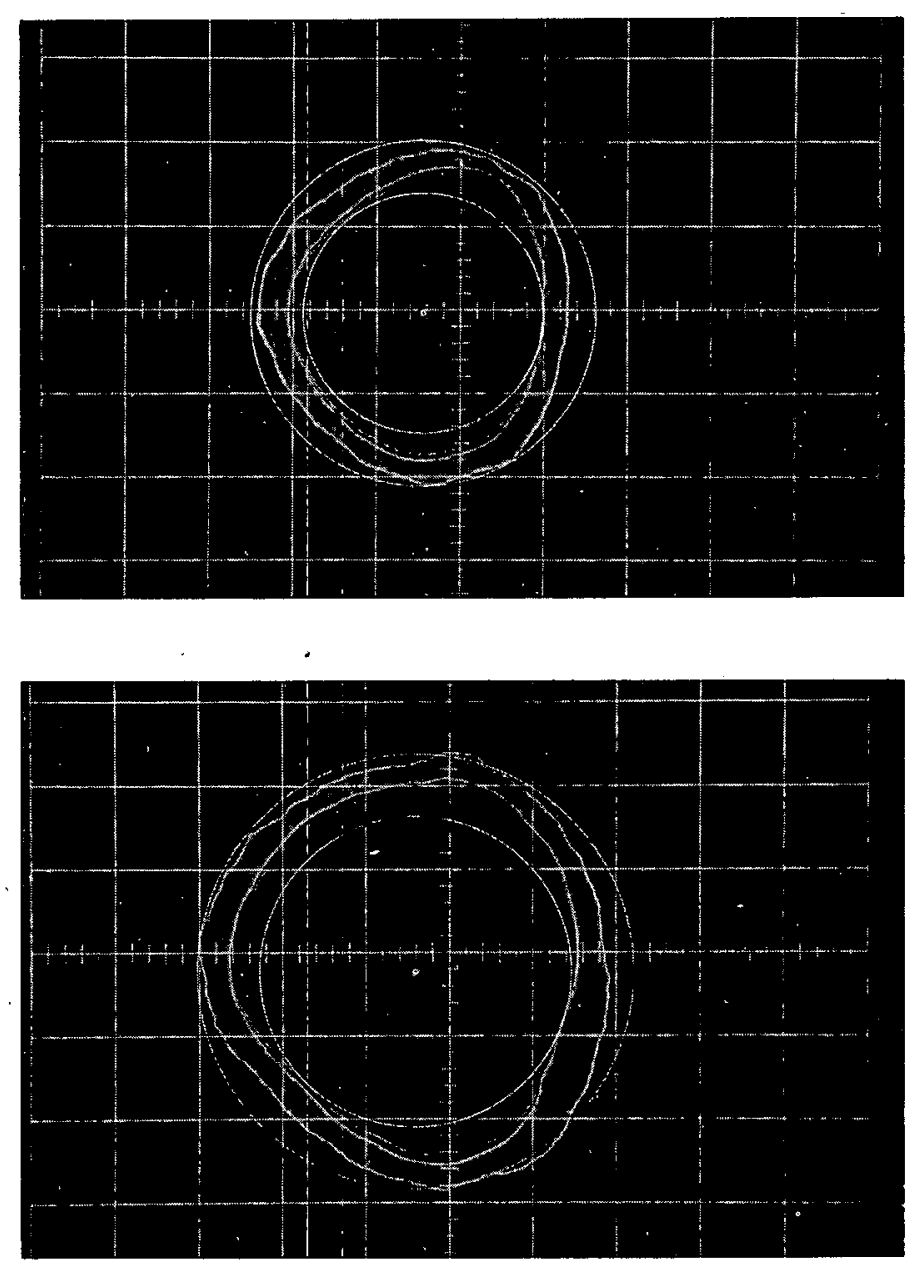

Figure 25. TYPICAL LISSAJOUS PATTERNS. (Spindle Runout Equals the Radius of the Circumscribed Circle Minus the Radius of the Inscribed Circle)

110,285 , and 460 pounds; for the 2,000-rpm tests, loads of 0,110 , and 285 pounds were used. Maximum face movement measured relative to the housing at $1,000 \mathrm{rpm}$ was 65 microinches and 230 microinches at 2,000 rpm. Both maxima occurred with a 285-pound load. The center of mass for this load was approximately five inches from the face of the spindle. The maximum movement measured for the 460-pound load with a center-of-mass location approximately seven inches from the face of the spindle was only 40 microinches, indicating a possible discrepancy in data or a change in environment during the two tests. This value is also the amount measured for the 110-pound load. Normal machining speeds are between 200 and $600 \mathrm{rpm}$, and movement encountered during these operations should be almost negligible since heat generation in the bearings is a function of the square of the speed and since heat dissipation at low temperatures is almost linear with temperature. Interpolation of these results indicates that the face movement will be around 20 microinches at $600 \mathrm{rpm}$ for the 285-pound load and less for the other load conditions. During these tests, the maximum forward-housing temperature rise recorded was $6.0^{\circ} \mathrm{F}$ at 2,000 


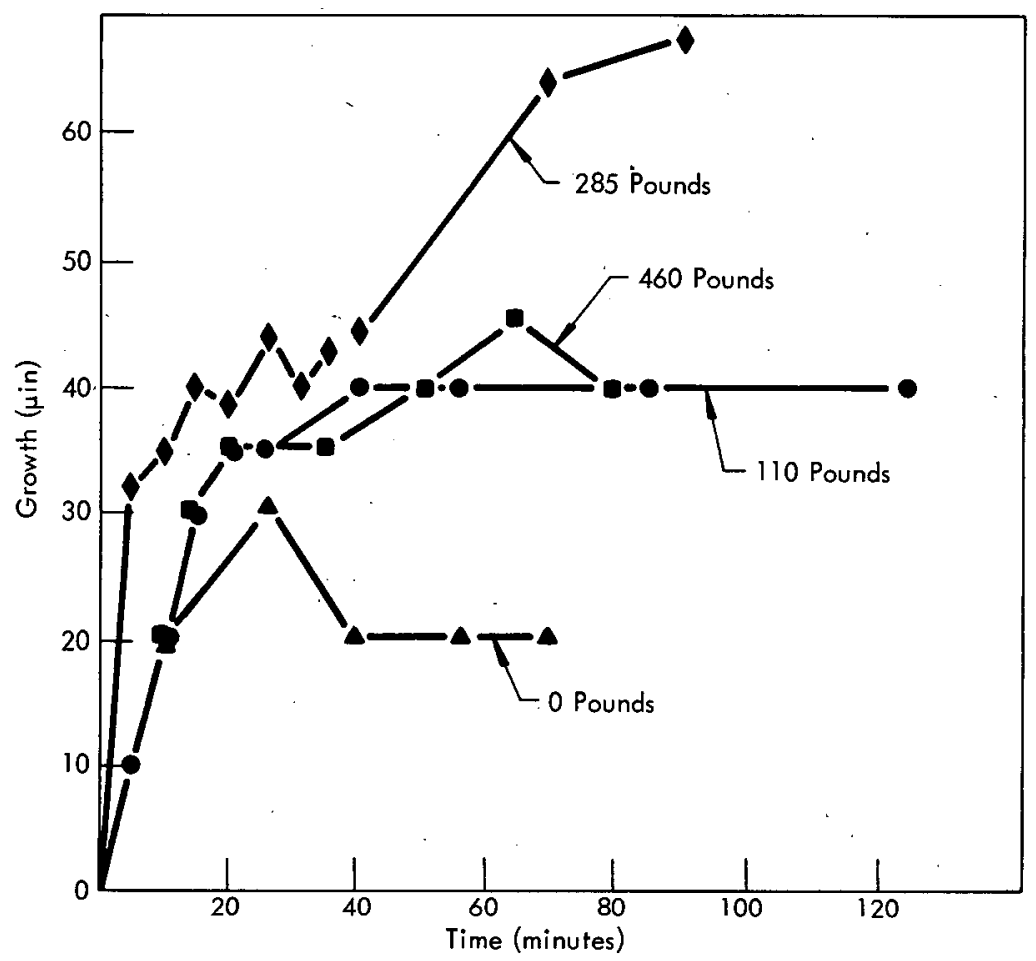

Figure 26. SPINDLE GROWTH AS A FUNCTION OF TIME UNDER VARIOUS LOADS. (AT 1,000 RPM)

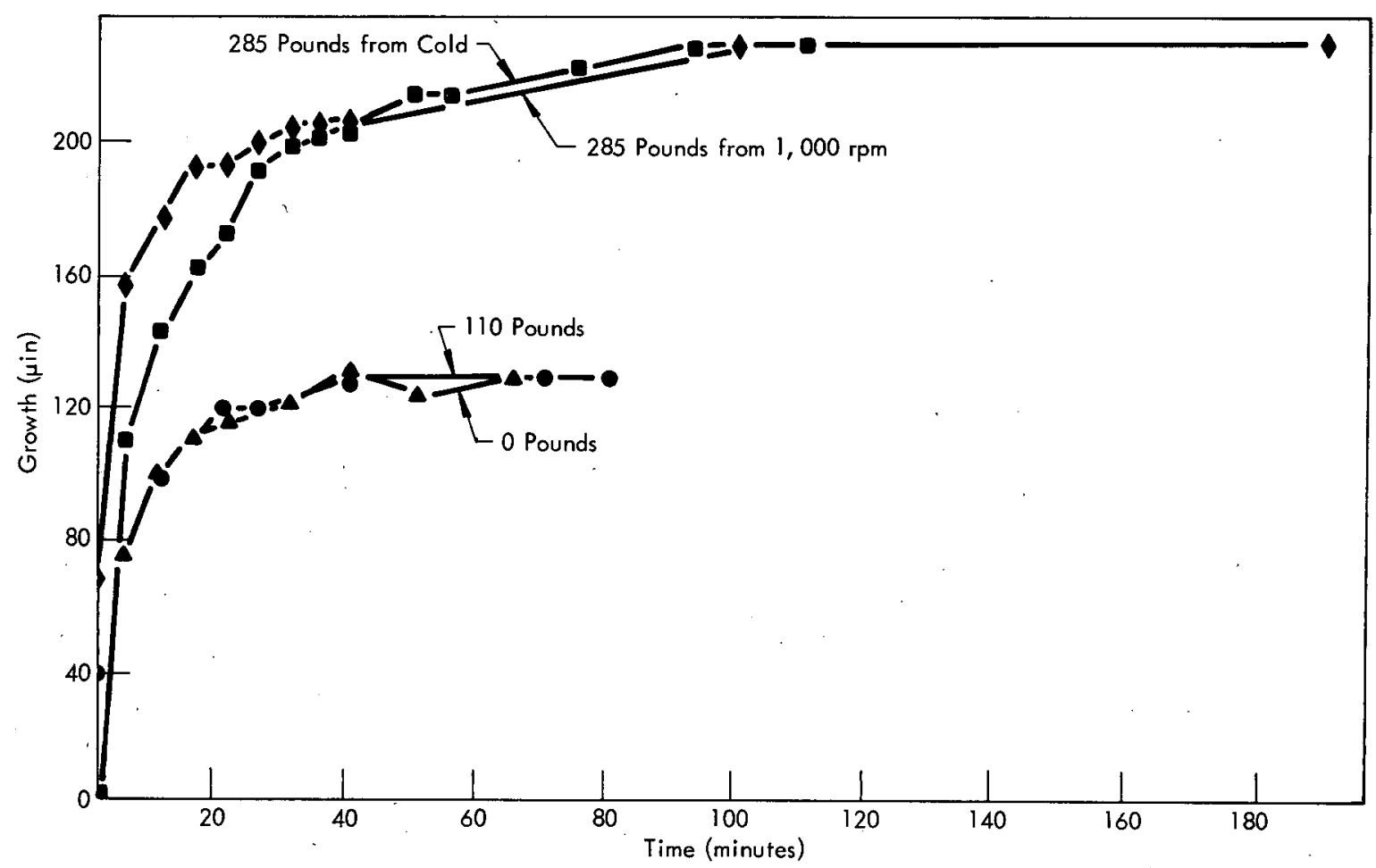

Figure 27. SPINDLE GROWTH AS A FUNCTION OF TIME UNDER VARIOUS LOADS. (At 2,000 RPM) 


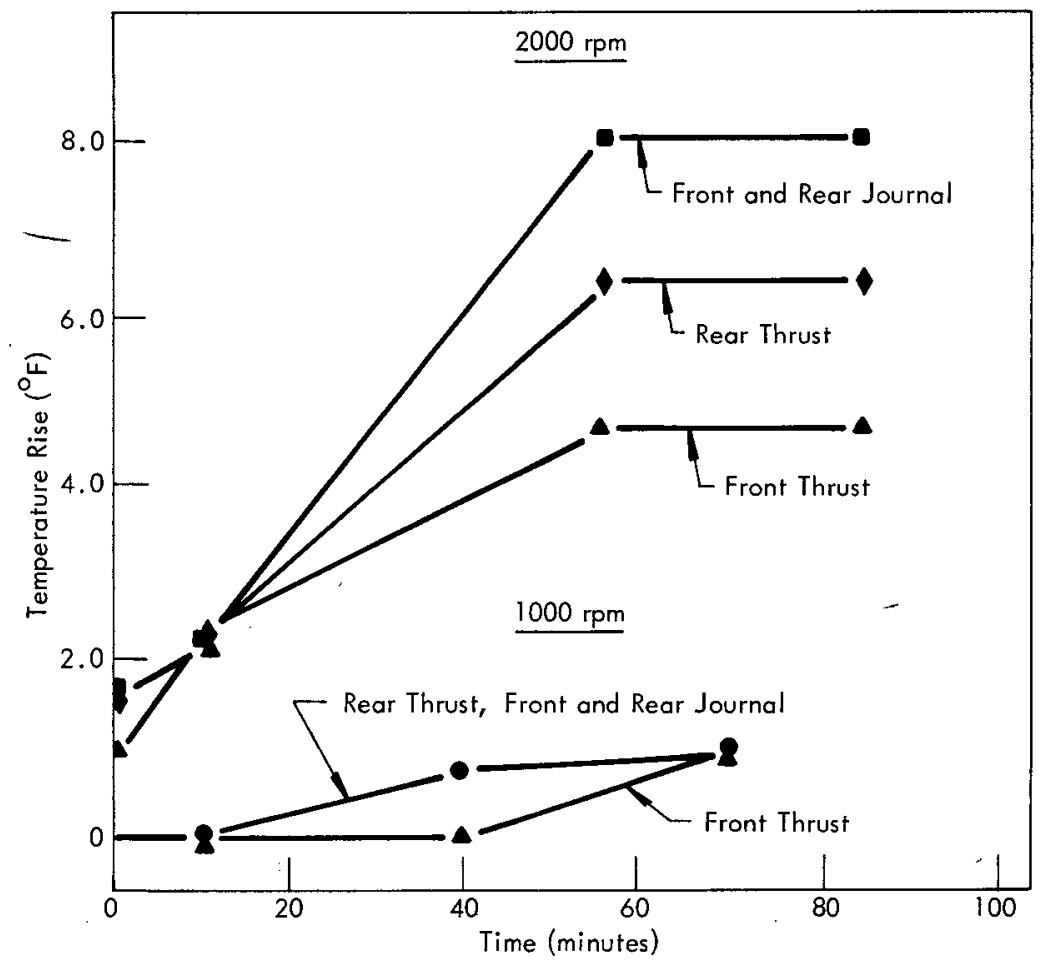

Figure 28. TEMPERATURE RISE OF THE BEARING PADS FOR A NOLOAD CONDITION. (At 1,000 and 2,000 RPM)

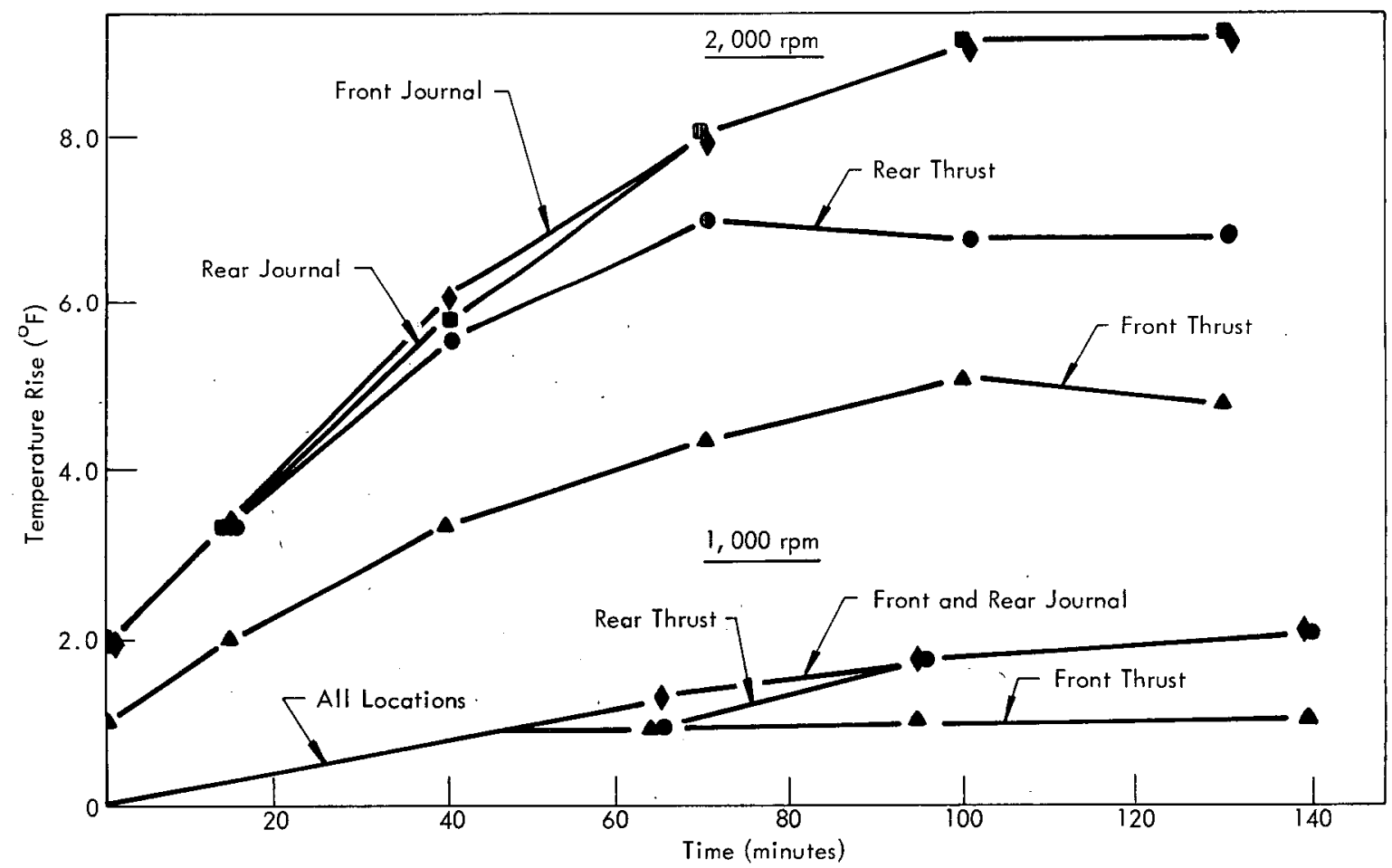

Figure 29. TEMPERATURE RISE OF THE BEARING PADS FOR A I10.POUND LOADED CONDITION. (At 1,000 and 2,000 RPM) 


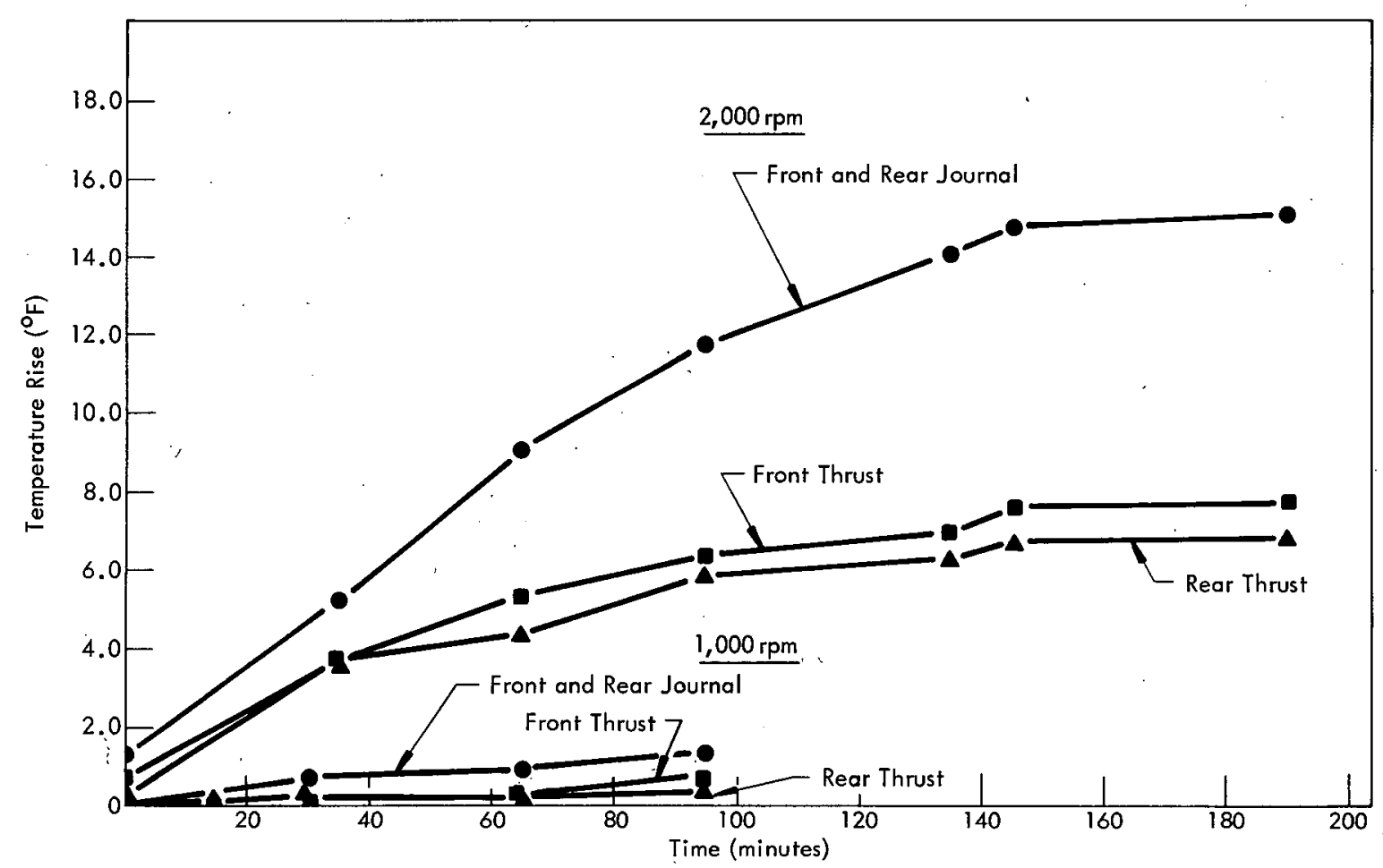

Figure 30. TEMPERATURE RISE OF THE BEARING PADS AND FRONT HOUSING FOR A 285-POUND LOADED CONDITION. (At 1,000 and 2,000 RPM)

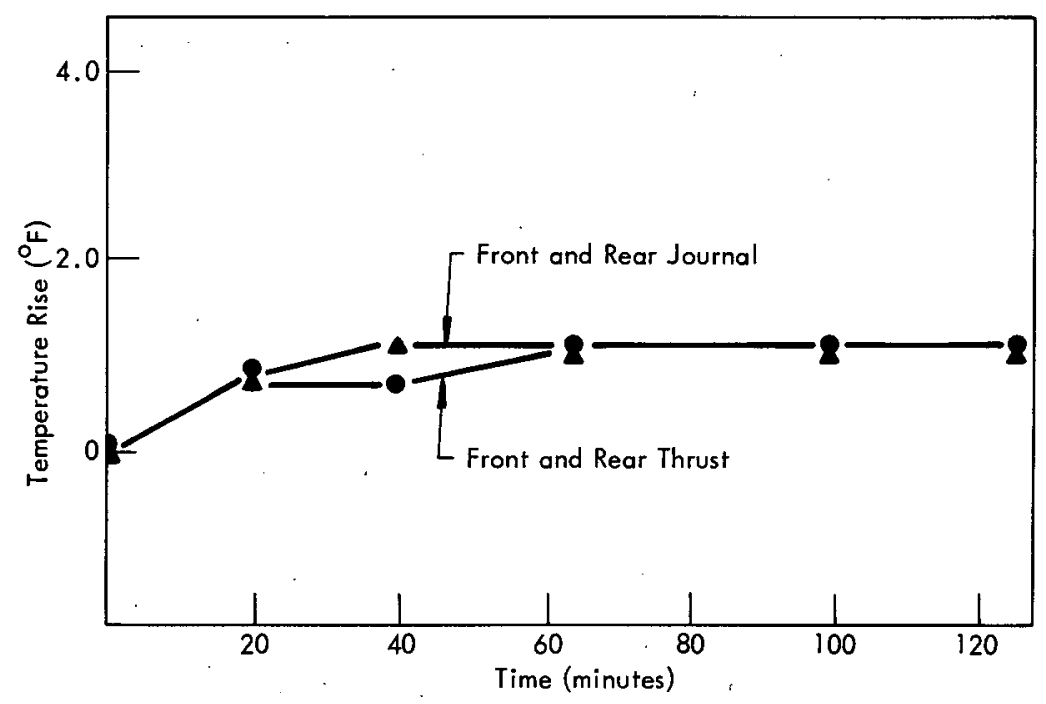

Figure 31. TEMPERATURE RISE OF THE BEARING PADS FOR A 460-POUND LOADED CONDITION. (A+ 1,000 RPM)

$\mathrm{rpm}$; at 1,000 rpm the rise was $2.0^{\circ} \mathrm{F}$. The shaft-face temperature increased approximately $10^{\circ} \mathrm{F}$ at $2,000 \mathrm{rpm}$ and $2^{\circ} \mathrm{F}$ at 1,000 rpm during the same tests. The word "approximately" is used because this measurement was made in each case after the spindle had been brought to rest. 
A radial-movement test made at a point five inches from the spindle face with the 110-pound load indicated a four-microinch horizontal movement and a 15-microinch vertical movement. This movement occurred in going from static to 2,000 rpm. For speeds to $600 \mathrm{rpm}$ it can be considered negligible.

Repeatability

A test of spindle positioning repeatability was conducted to determine if going from a pressurized condition to zero film pressure and back to a pressurized condition would change the spindle position. This action was measured at a point 13 inches from the spindle face. The test indicated a repositioning accuracy of \pm 5 microinches.

Rotational Accuracy Under Load

The final test performed was the measurement of the spindle runout at a point 13 inches from the spindle face with a 460-pound load on the spindle. This test was performed by machining one of the test specimens for roundness and flatness at 500 rpm and using the Dynagages to measure the radial runout at 20,500, 1,000, and $1,500 \mathrm{rpm}$. The radial runout measured with the Dynagages was 14 microinches at $20 \mathrm{rpm}, 20$ microinches at 500 and 1,000 rpm, and 18 microinches at 1,500 rpm. The results of the specimen test indicated a 23 -microinch radial runout and 15microinch end camming. The setup used is shown in Figure 32.

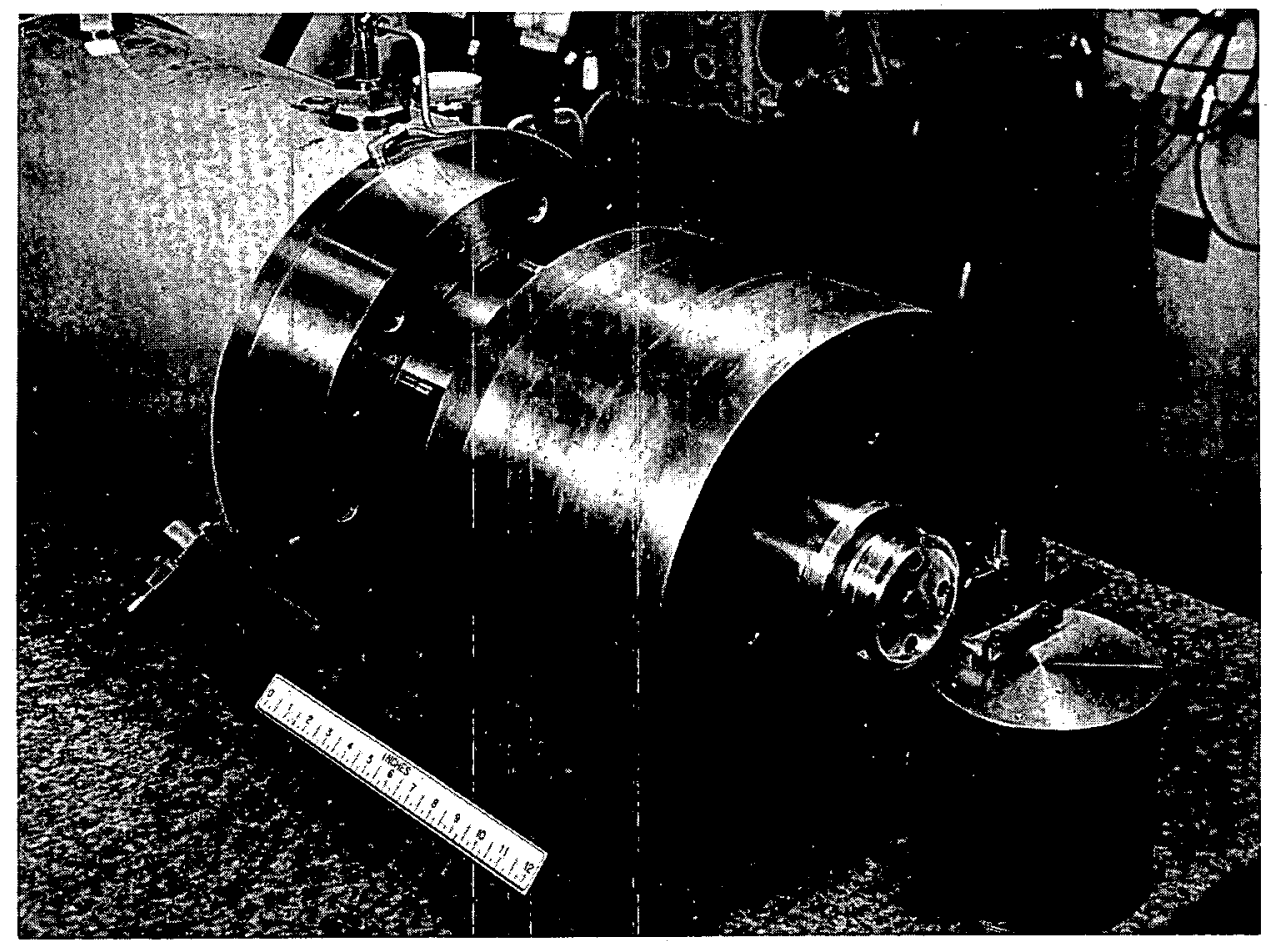

116601

Figure 32. ARRANGEMENT FOR MACHINING A TEST SPECIMEN WITH THE SPINDLE UNDER A 460 POUND LOAD. 
Bearing Durability

During evaluation of the air-bearing spindle, a failure of the rear-thrust unit occurred at a speed of $2,500 \mathrm{rpm}$. Investigation revealed that the runner deflected radially as the spindle length increased during operation, causing the inner radial area to come in contact with the carbon pad. This problem was attributed to the lack of stiffness in the thrust runner and the position of contact with the runner of the rearthrust deflection ring. The unit was redesigned, which eliminated this condition. Although this failure caused hard rubbing of the carbon pad (as evidenced by visual observation of the runner), no rotational accuracy or air-flow increase occurred. During another test of the spindle, the failure of an air line feeding a front-journal pad caused the 250-pound rotor to stop from a speed of 1,500 rpm in approximately five seconds. The temporary plastic tubing used in preliminary testing was removed and replaced with steel tubing. Subsequent testing of the spindle indicated no change in the accuracy or performance of the spindle. Although hard rubbing occurred during this failure, no significant damage to the pad or shaft was apparent from its performance. The spindle was not disassembled and examined, but the apparent absence of damage from this failure indicates the durability of the porous carbon pad design. 


\section{APPENDIX}

\section{FLEXURE RING DEFORMATION}

The flexure ring consists basically of a flat ring with a hub in the center. Loading of the ring occurs from the thrust pad at its edge. The spherical washer and nut support the ring at the hub. For small deflections, it can be assumed that bending occurs along the radial length of the plate from the hub out to the edge, with maximum deflection at the edge.

Deflection at the edge can be determined from: (6)

$y_{\text {max }}=\frac{3 W(m-1)}{4 m^{2} \pi E t^{3}}\left[\frac{a^{4}(3 m+1)-b^{4}(m-1)-2 a^{2} b^{2}(m+1)-8 m a^{2} b^{2} \ln \frac{a}{b}-4 a^{2} b^{2}(m+1)\left(\ln \frac{a}{b}\right) 2}{a^{2}(m+1)+b^{2}(m-1)}\right]$

where:

W represents the load in pounds,

$y$ the deflection in inches,

E the modulus of elasticity in pounds per square inch,

$m$ the reciprocal of Poisson's ratio,

t the thickness of plate in inches, and

$a$ and $b$ the length dimensions in inches as indicated by Figure A-1.

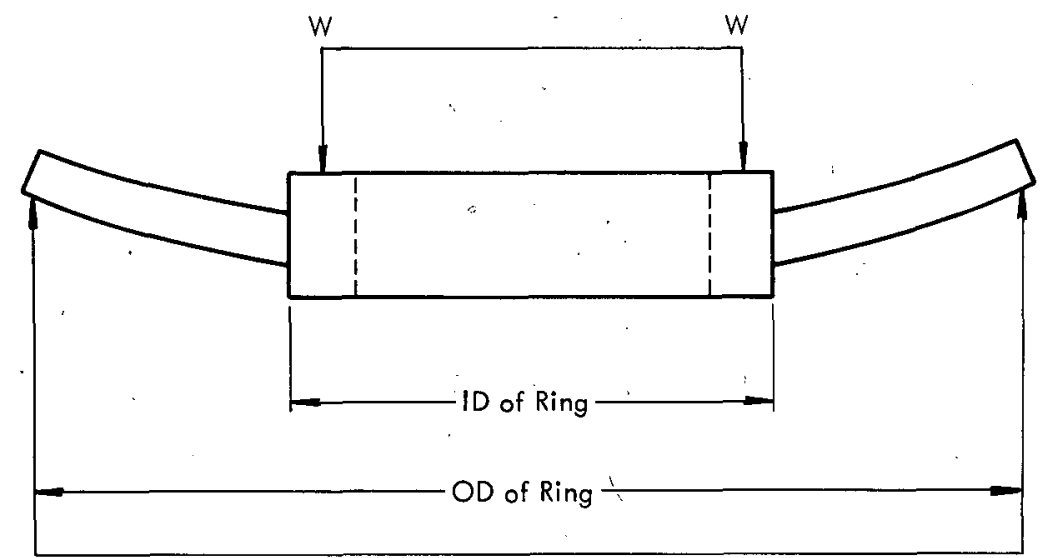

Figure A-1. DIAGRAM OF FLEXURE RING UNDER LOAD. 
The load, $W$, is determined from

$$
W=P A,
$$

where:

$P$ represents the air-film pressure, and

A the thrust area.

The maximum stress in the ring which occurs at the inner edge was determined from:

$$
S_{r_{\max }}=\frac{3 W}{2 \pi t^{2}}\left[\frac{2 a^{2}(m+1) \ln \bar{b}+a^{2}(m-1)-b^{2}(m-1)}{a^{2}(m+1)+b^{2}(m-1)}\right] \text {, }
$$

where:

$S_{r}$ represents the stress in the ring in pounds per square inch, and

In the natural logarithm:

The purpose of the flexure ring unit is to apply a preload to the thrust bearings and thereby take up shaft expansion to the rear. This arrangement eliminates the forward shaft expansion except for the front-thrust runner and the change in the frontthrust air-film thickness.

Shaft expansion due to temperature rise was determined from:

$$
\Delta_{\mathrm{f}}=\alpha \mathrm{l}_{\mathrm{s}} \Delta \mathrm{T},
$$

where:

$\Delta_{f}$ represents the thermal expansion in inches,

$I_{s}$ the length of shaft in inches,

a the thermal expansion in inches per inch, and

$\Delta T$ the temperature rise in ${ }^{\circ} \mathrm{F}$. 
The change in the front-thrust air-film thickness due to a change in preload can be determined from:

$$
\Delta_{t_{f}}=\frac{W\left(\frac{\Delta_{t}}{y_{\text {max }}}\right)}{H},
$$

where:

$\Delta_{f_{f}}$ represents the change in film thickness in inches, and

$H$ the film stiffness of the front thrust bearing. 


\section{REFERENCES}

(1) Richards, J. B.; Practical Developments in Precision Machining Techniques, Y-DA-1068; Union Carbide Corporation-Nuclear, Division, Y-12 Plant, Oak Ridge, Tennessee; January 5, 1966.

(2) Steger, P. J.; Air-Bearing Spindle for Machine Tools-Spherical Design, Y-1581; Union Carbide Corporation-Nuclear Division, Y-12Plant, Oak Ridge, Tennessee; to be published.

(3) Fuller, D. D.; Theory and Practice of Lubrication for Engineers; John Wiley and Sons, Inc, New York, New York (1956).

(4) Lewis, T. G. and Whitten, L. G.; Machining and Measurement to Submicron Tolerances, Y-KE-204 (Revised); Union Carbide Corporation-Nuclear Division, Y-12 Plant, Oak Ridge, Tennessee; September. 8, 1966.

(5) Brown, A. I. and Marco, S. M.; Introduction to Heat Transfer, p 126; McGrawHill Book Company, Inc, New York, New York (1951).

(6) Roark, R. J.; Formulas for Stress and Strain, p 201; McGraw-Hill Book Company, Inc, New York, New York (1954). 


\section{AVAILABLE DRAWINGS}

Drawings for the air-bearing spindle described in this report, $Y-1578$, have been made available, exceptE-M-54195, through the Clearinghouse for Federal Scientific and Technical Information, (CFSTI), National Bureau of Standards, US Department of Commerce, Springfield, Virginia 22151. These drawings are listed below:

\begin{tabular}{|c|c|}
\hline $\begin{array}{l}\text { Drawing } \\
\text { Number }\end{array}$ & Title \\
\hline$E-M-54185$ & Air Spindle Assembly \\
\hline$E-M-54186$ & Air Spindle Housing \\
\hline$E-M-54187$ & Air Spindle Shaft \\
\hline$E-M-54188$ & Air Spindle Front Thrust Bearing \\
\hline$E-M-54189$ & Air Spindle Journal Shoe \\
\hline$E-M-54190$ & Air Spindle Rear Thrust Bearing \\
\hline$E-M-54191$ & Air Spindle Thrust Flexure Unit \\
\hline$E-M-54192$ & Air Spindle Graphitar Pads \\
\hline$E-M-54193$ & Air Spindle Miscellaneous Part Detail \\
\hline$E-M-54194$ & Air Spindle Laps \\
\hline$E-M-54195$ & Air Spindle Seal \\
\hline$E-M-56944$ & 7-Inch Air Bearing Improved Thrust Unit \\
\hline$C-M-30716$ & 7-Inch Air Bearing Improved Thrust Unit \\
\hline
\end{tabular}

Drawing E-M-54 195 will be made available through (CFSTI). 